\title{
The Cortical Component of Experience-Dependent Synaptic Plasticity in the Rat Barrel Cortex
}

\author{
Kevin Fox \\ Department of Physiology, University of Minnesota, Minneapolis, Minnesota 55455
}

\begin{abstract}
Rats were raised with altered tactile experience from PO by removing all but one vibrissa (D1) from one side of the face (D1-spared animals). This procedure (univibrissa rearing) has previously been shown to cause neurons in cortical barrels surrounding D1 to develop greater than normal responses to D1 vibrissa stimulation and smaller than normal responses to principal vibrissa stimulation (Fox, 1992). In this study, it was found that the potentiated D1 responses could be attenuated by acute microlesions placed in the D1 barrel, while principal vibrissa responses were unchanged or even slightly elevated for the same cases. The ratio of the average D1 to principal vibrissa response was approximately proportional to the volume of tissue damaged in the D1 barrel. This result implies that the synaptic plasticity seen in cortex of D1-spared animals is due to synaptic changes that take place within the barrel cortex rather than to relay of changes occurring at a subcortical level. In addition, lesions aimed at the septum between D1 and an adjacent barrel aimost completely abolished responses to D1 stimulation in that barrel, including short-latency responses (5$10 \mathrm{msec}$ ). Only neurons severed horizontally from D1 were affected. Neurons that maintained a connection with the D1 barrel via a bridge of septal tissue preserved their usual elevated levels of response to D1 stimulation and their aberrant short-latency responses. This result implies that pathways radiating out from the D1 barrel/column, and connecting neurons in the D1 barrel to cells in surrounding barrels, undergo synaptic plasticity induced by univibrissa rearing.
\end{abstract}

[Key words: somatosensory, vibrissa, neocortex, intracortical, Jesion, potentiation]

The difficulty of disentangling cortical from subcortical plasticity has been a major impediment to understanding plasticity mechanisms in the somatosensory cortex. Changes in receptive ficld properties have been observed in the cortex in reply to manipulation of the periphery on many occasions, but it has not been clear whether the changes observed were due to synaptic plasticity occurring at cortical synaptic connections or whether the changes were a passive reflection of alterations oc-

\footnotetext{
Received Dec. 20, 1993; revised May 27, 1994; accepted June 9, 1994.

I am most grateful to Cheryl Pulaski and Xinren Li for technical assistance, to Eric Humke and Leah Solberg for help with the data and lesion analysis, and to Sharon Juliano and Stanislaw Glazewski for critical reading of the text. This work was supported by NIH Grant NS27759.

Correspondence should be addressed to Dr. K. Fox, Department of Physiology, University of Minnesota, 6-255 Millard Hall, 435 Delawarc Street S.E., Minneapolis, MN 55455.

Copyright (C) 1994 Society for Neuroscience $0270-6474 / 94 / 147665-15 \$ 05.00 / 0$
}

curring at a preceding subcortical level. The problem is particularly acute for students of somatosensory cortex, because plasticity has been demonstrated to occur in nearly every subcortical element of the somatosensory system in which it has been sought, for example, in the spinal cord (Devor and Wall, 1981; Fitzgerald, 1985), dorsal column system (Basbaum and Wall, 1976; Rasmusson, 1988), trigeminal system (Waite, 1984), and thalamus (Nicolelis et al., 1991; Garraghty and Kaas, 1992). By contrast, the locus of plasticity has not been ambiguous in the visual cortex, making it a popular model system for studying the mechanisms of cortical plasticity (Wiesel and Hubel, 1963). Ocular dominance plasticity is known to be a cortical phenomenon because the first binocular cells in the pathway occur in the cortex. Similarly, plasticity of direction selectivity is known to be a cortical phenomenon because the first direction-selective cells in the pathway occur in the cortex. On the other hand, receptive field properties are approximately similar at different levels in the somatosensory system, and body maps of similar form occur at each stage of the pathway.

It has recently become possible to investigate the origin of plasticity observed in the cortex as a result of two recent findings. First, it has been found that rats raised from $\mathrm{PO}$ with just the D1 vibrissa intact and the other vibrissae carefully removed so as not to damage the follicle (D1-spared animals) show a larger area of cortex dominated by the D1 vibrissa (Fox, 1992). Most neurons in barrels surrounding Dl exhibit greater responses to D1 stimulation than to their nominal principal vibrissae. Second, it has been demonstrated that partially ablating a single cortical barrel in normally raised animals reduces the responses of neurons in an adjacent barrel to that barrel's principal whisker. So, for example, ablating the D2 barrel prevents cells in the surrounding barrels from responding to D2 vibrissa stimulation (Armstrong-James et al., 1991a). This observation implies that little subcortical divergence of vibrissa information is relayed to cortex in normal animals. In this series of experiments we used similar techniques to explore whether the increased divergence of D1 excitation seen in D1-spared animals was due to increased cortical or subcortical divergence.

The experiment is outlined in Figure 1. If the increased divergence occurs subcortically or in the thalamocortical link, then a lesion of the D1 barrel should leave the increased D1 representation unaffected in neighboring barrels. If, however, the "potentiated" pathway is cortical in origin and emanates from the Dl barrel, then ablation of the D1 barrel should abolish the D1 representation in neighboring barrels. Theoretically, then, this paradigm should be capable of distinguishing between the cortical and the subcortical components of plasticity observed in the cortex.

On first inspection, it might seem an equivalent experiment 


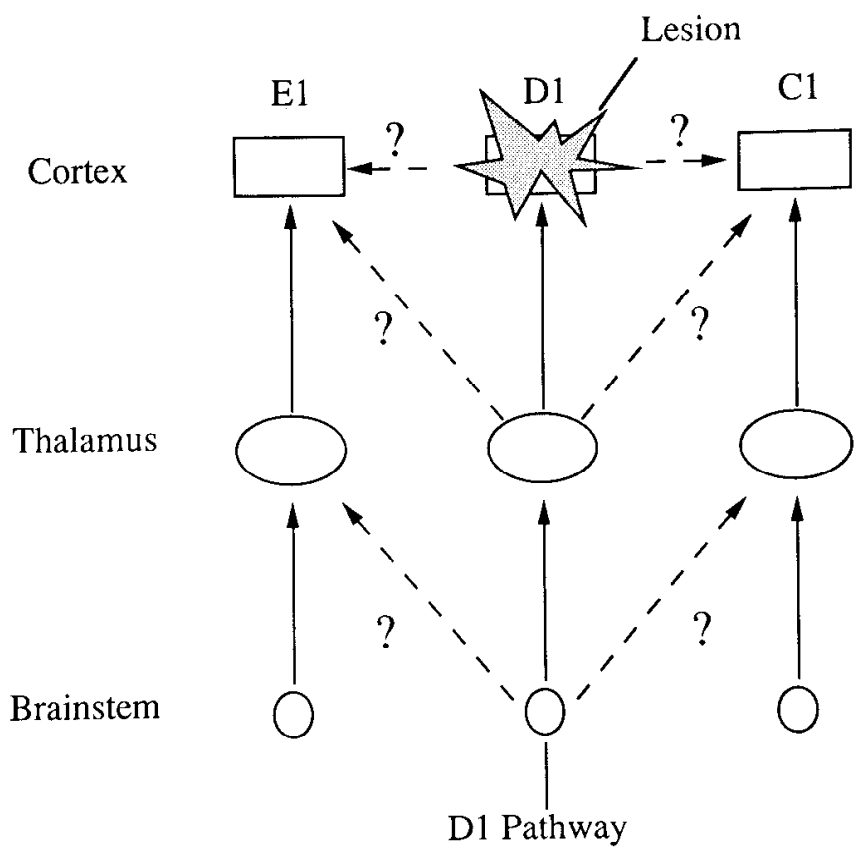

Figure 1. Diagram illustrating the possible sources of divergence of Dl vibrissa information en route from the brainstem to the cortex. The dashed lines indicate pathways that may be potentiated by univibrissa rearing. Theoretically, only those pathways emanating from the D1 barrel should be affected by lesions destroying the D1 barrel.

to record from the thalamus in a D1-spared animal to answer the same question. However, such an approach would give an estimate only of the plasticity occurring subcortically, not the component of subcortical plasticity projected onto the cortex. The advantage of the present paradigm is that the thalamocortical response transformation, which is almost certainly not linear (see Armstrong-James et al., 1991a,b), is automatically taken into account by making all measurements from cortical cells.

One further aspect of plasticity can also be examined in these experiments: that due to changes in the thalamocortical projection. Neurons in barrels surrounding D1 show short-latency responses to stimulation of the D1 vibrissa in univibrissa animals, unlike normally reared animals (Fox, 1992). It is likely that these aberrant short-latency responses are due to thalamocortical axons diverging from the D1 barreloid to a wider cortical territory than normal. If so, one might expect them to survive destruction of the D1 barrel (Fig. 1). However, this prediction assumes that the axons do not course through the D1 barrel before projecting to the surrounding barrels.

$\Lambda$ nimals were deprived from $\mathrm{P0}$, as plasticity is most likely to be subcortical at that age. The results demonstrate that the plasticity observed in the cortex as a result of univibrissa rearing is mainly if not exclusively due to changes occurring in cortical and/or thalamocortical pathways. In addition, using a novel form of discrete lesion to sever one barrel from another, we have begun to restrict the number of intracortical pathways that could possibly be involved in this form of cxpcrience-dependent plasticity.

\section{Materials and Methods}

\section{Subjects}

Male and female Long-Evans rats from six different litters were used for these studies. Of the animals that received acute microlesions of the
D1 harrel, 14 were reared as univibrissa animals and four were reared normally. These are compared with 19 control animals without acute cortical microlesions, of which seven were reared as univibrissa rats and 12 were reared normally.

\section{Deprivation technique}

The vibrissa deprivation has been described in detail in an earlier publication (Fox, 1992). Briefly, it consisted of removing all but the D1 vibrissa from the face bi-daily starting on $\mathrm{P0}$ (within $12 \mathrm{hr}$ of birth) and continuing for approximately $60 \mathrm{~d}$. Just 4-7 d before recording, the deprived vibrissae were allowed to regrow so that they could be stimulated during the recording session. This deprivation procedurc docs not cause degeneration of the apparatus of the follicle in the way that a lesion does. Myelinated and unmyelinated axons do not degenerate ( $\mathrm{Li}$ and Fox, unpublished observations) and the regrown vibrissae evoke responses as powerful as those recorded in normal animals for many layer IV cells when unmasked by cortical lesions (see Results).

\section{Surgery}

The details of the surgery are identical to those described previously (see Fox, 1992). Anesthesia was induced with metafane and maintained with urethane $(1.5 \mathrm{gm} / \mathrm{kg}$ whole body weight). Anesthetic depth was monitored throughout the experiment by testing reflexes and observing the spontaneous firing rate of the neurons. Supplements of urethane ( $10 \%$ of original dose) were administered to maintain a state where the hind limb withdrawal reflex was sluggish but present and the layer $V$ rate of spike burst generation was in the 1-2 Hz range (Fox and Armstrong-James, 1986). The cranium was removed between 4-7 mm lateral to the midline and 1-4 mm caudal to bregma by careful drilling. Small holes were made in the dura $(1-200 \mu \mathrm{m})$ through which the electrode could be introduced.

\section{Electrodes}

Single-barreled, carbon-fiber microelectrodes were used to record from neurons extracellularly. Signals were amplified, filtered, and displayed as describcd previously (Fox, 1992). Spikes were isolated using a voltage window discriminator and spike events were stored as peristimulus times using a CED 1401 and a computer running SPIKE2 software (Cambridge Electronic Design, UK). Spike waveform shape was monitored during recording to ensure good spike isolation. Poststimulus time histograms and rasters were monitored on line during stimulation.

\section{Stimulus}

The stimulus was a $200 \mu \mathrm{m}$ vertical deflection of the vibrissa $10 \mathrm{~mm}$ from the face, delivered at $1 \mathrm{~Hz}$. The stimulator was a fast piezoelectric bimorph wafer attached to a lightweight glass capillary touching the vibrissa. All stimulus parameters were identical to those used in three previous studies (Armstrong-James and Fox, 1987; Armstrong-James ct al., 1991a; Fox, 1992) to allow comparison of data between studies (for a complete description, see Fox, 1992).

\section{Recordings and lesion placement}

For each animal, exploratory penetrations were made to assess the locations of the different barrels, the lesions were made, and, starting 1$2 \mathrm{hr}$ later, the effects of the lesions on neuronal responses were assayed.

Prelesion search. The location of the center of the D1 barrel or the location of the septum between two barrels was estimated by successive approximation. An initial estimate of the location of the D1 barrel was made by recording evoked potentials $(0.1 \mathrm{~Hz}$ to $8 \mathrm{kHz}$ bandwidth) from the surface via the electrode. The first penetration was made at a point where the evoked potentials generated by D1 vibrissa stimulation appeared largest. The electrode was driven down to layer IV where the receptive field of several cells was determined using the standard automatic stimulus and PSTH analysis. From a consideration of the relative magnitude and latency of response to the different vibrissa, the location of the electrode within the barrel field could be guessed fairly accurately. The identity of the barrel could be determined from knowing which vibrissa generated the fastest response, since this is almost always the principal vibrissa (except for D1 responses in D1-spared animals that also occur outside the D1 barrel). To which side of the barrel the electrode was located could be determined by finding which surround receptive vibrissa generated the largest responses; that is, a cell with a 
fast responsc only to D1 that responded to D2 and E2 but not to $\delta, \mathrm{C} 1$, and E1 was almost certainly located on the corner of the D1 barrel nearest D2 and E2. Usually three exploratory penetrations were necessary to gauge the disposition of the barrels. Using the stereotaxic coordinates logged from each penetration, a map could be sketched of the barrel locations.

Making the lesions. Usually the fourth penetration was in a location estimated to be where the lesion was required. Again, receptive fields were measured from several cells as the penetration was made. Provided these measurements corroborated our expected position, the electrode was advanced to about $680 \mu \mathrm{m}$ from the surface and an electrolytic lesion produced by passing direct current through the tip for $10 \mathrm{sec}(20$ $\mu \mathrm{A}$ for a large lesion of $150 \mu \mathrm{m}$ radius and $8 \mu \mathrm{A}$ for a small lesion of $50 \mu \mathrm{m}$ radius). The exact parameters used are described in the Results, as a varicty of lcsion sizes were produced for different experimental protocols. If two or more lesions were made, lesions subsequent to the first had to be made "blind," without benefit of recording responses to vibrissa stimulation, as the first lesion invariably blocked cortical responses in neighboring tissue for a short time.

Postlesion assay. One or two hours after the last lesion had been made, we recorded in barrels surrounding D1 to assay responses to vibrissa stimulation. In the cases where the intention was to destroy the entire D1 barrel, an effort was made to sample from several barrels surrounding D1, progressing in a circle around the lesion. At least three and usually more assay penetrations were made per animal. In the cases where the intention was to sever D1 from D2 with a septal lesion, most of the assay penetrations were made in D2. However, one penetration was also made in one other barrel neighboring D1 calculated not to have been severed from D1.

After inserting the electrode in the brain, it was left to sit for several minutes before recording the first cell, which improved the chances of recording from the most superficial cells $(50-250 \mu \mathrm{m})$ in each penetration. Neurons were sampled from layers II/III and IV at intervals of 150-200 $\mu \mathrm{m}$. Neurons were recorded at the site encountered unless they were isolated poorly. When necessary, the electrode was moved in 20 $\mu \mathrm{m}$ steps until isolation was adequate. The D1 vibrissa was stimulated for each cell, and usually two or three other vibrissa that were candidates for the principal vibrissa. After recording from layer IV, a brief excursion was made into layer $\mathrm{V}$ to measure the spike-burst rate. The electrode was then returned to the previous layer IV location and a small electrolytic lesion made to mark the recording location $(2 \mu \mathrm{A} \mathrm{DC}, 10 \mathrm{sec}$, tip negative).

\section{Histology}

On completion of the recording session, the animal was deeply anesthetized to a state where all reflexes were abolished. The animal was then perfused through the heart with $0.1 \mathrm{M}$ phosphate-buffered saline to exsanguinate, followed by $10 \%$ formalin and $10 \%$ sucrose in formalin The brain was then carefully removed, flattened as described before (Woolsey and Van der Loos, 1970; Fox, 1992), and left overnight in $20 \%$ sucrose in formalin. Sections of known thickness (either 50 or 60 $\mu \mathrm{m})$ were cut on a freezing microtome and the tissue reacted for cytochrome oxidase (Wong-Riley, 1979). In some experiments alternate sections were stained for Nissl substance using standard methylenc bluc or thionin protocols.

\section{Data analysis}

Lesions. In initial experiments, alternate Nissl and cytochrome oxidase sections were compared. Lesions were found to be composed of an inner cavity devoid of tissue and an outer halo of damaged tissue that appeared pale in cytochrome oxidase sections and cell sparse in Nissl sections. The boundary of the outer halo was taken as the limit of the lesion.

By comparing adjacent sections it could be seen that the cell-sparse region corresponded almost exactly to the cytochrome oxidase-deficient zone (Fig. 2). The boundary of the cytochrome-deficient region was easier to see than the cell-sparse region, however, in part because the boundary was often masked by densely stained glia in the Nissl sections and in part because the boundary was continuous in the cytochrome sections but effectively discontinuous in the Nissl sections, being based on an estimate of cell density.

Recording penetrations made inadvertently within the cytochrome oxidase-deficient zone revealed long tracks without vibrissa responses or spontaneous activity. This supported our notion that the outer halo encompassed the true extent of the damaged tissue. Camera lucida drawings (magnification $\sim 50 \times$ ) were made of each horizontal section through the brain outlining the border of the cytochrome oxidase-deficient zone and any barrels present in the section. The locations of the recording sites were also marked within the barrel field. Areas of the lesion and the barrels were measured using a graphics tablet and sIGMA SCAN software (Jandel, CA) calibrated by drawing a calibration graticule placed under the microscope. Knowing the section thickness, the volumes of the lesions and barrels could be calculated. This allowed us to determine how much of the barrel had been destroyed by the lesion.

For most cases, estimating the volume of D1 that had been damaged was simply a matter of tracing around the border of D1 on each section to arrive at the D1 barrel volume and tracing around the outline of the lesion within the D1 barrel to measure the lesion volume within D1. In cases where the lesions were very large it was impossible to trace the outline of the D1 barrel on each section. In these cases we extrapolated between the clearly demarcated D1 barrel outlines where possible, and where not possible the barrel volume was estimated by measuring the D2 barrel volume and applying a ratio to predict the Di barrel volume. The ratio was based on the ratio of areas of the D1 and D2 barrel where both barrels occurred on the same section. Where the D1 barrel was damaged to the extent that its outline could not be seen clearly on any section, the volume of the residue was calculated and subtracted from a predicted D1 volume based on the D2 volume for that case multiplied by 1.32 (which was the mean ratio of D1:D2 volume for the cases where the D1 volume could be determined). These extra calculations for the largest lesions probably resulted in the estimates of D1 volume damage being less accurate for the larger lesions.

To estimate the damage to the D1 column in layers II and III, we measured the volume of the lesion in layers II/III overlying the D1 barrel and divided this value by the volume occupied by layers II/III within the D1 column. The volume of the D1 column in layers II/III was calculated by multiplying the area of widest girth of the D 1 barrel by the thickness of layers II/III $(\sim 50-450 \mu \mathrm{m})$. The percentage of this volume damaged by the lesion was measured by superimposing the camera lucida drawing of the lesion within layer II/III on the D1 barrel for each layer II/III section containing the lesion and measuring the area of overlap using the graphics tablet. The two images were superimposed using blood vessels, the lesion center itself, and any recording lesions as reference points.

\section{Vibrissa responses}

Latency and poststimulus time histograms. Detailed methods have been described elsewhere (Fox, 1992). Briefly, poststimulus and latency histograms were generated off line to analyze the data using a CED 1401 and a SPIKE2 data analysis program. Response magnitude and modal latency of response were calculated automatically by the program for each vibrissa.

Average vibrissa response. The average response magnitude of a samplc of ncurons to stimulation of the D1 and principal vibrissa was calculated for each animal. The response magnitude of a given cell was defined as the number of spikes occurring within a 5-50 msec time window in reply to 50 stimuli, after subtracting the number of spikes due to spontaneous activity. The average response for a particular vibrissa was averaged for each penetration by summing the individual response magnitudes and dividing by the number of cells. The individual penetration averages were then averaged in turn to arrive at an overall average response magnitude for each animal. Penetration averages were calculated first to overcome differences in the numbers of cells recorded in different penetrations.

The response to D1 stimulation for each animal was then usually divided by the average principal vibrissa response for that animal to account for differences in overall level of excitability between animals. This is referred to in the text as the strength of response or the D1 representation.

Curve fitting. SIGMAPLot (Jandel, CA) software was used to generate regression fits for the data. This software uses a least squares method of estimating curve fits. Regression coefficients $(r)$ are automatically calculated using this program and are to be found in the text where appropriate as the coefficient of determination $\left(r^{2}\right)$.

Vibrissa dominance histograms. The vibrissa dominance was calculated for cells located in barrels surrounding D1 by expressing the response magnitude of each cell to stimulation of D1 relative to its response magnitude to principal vibrissa stimulation. The function $F$ was calculated where $F=\mathrm{Dl} /(\mathrm{Dl}+\mathrm{P})$ and $\mathrm{Dl}$ and $\mathrm{P}$ are the number of spikes per stimulus evoked by D1 and principal vibrissa, respectively. This value varies between 0 and 1 , where 0 indicates no response to 

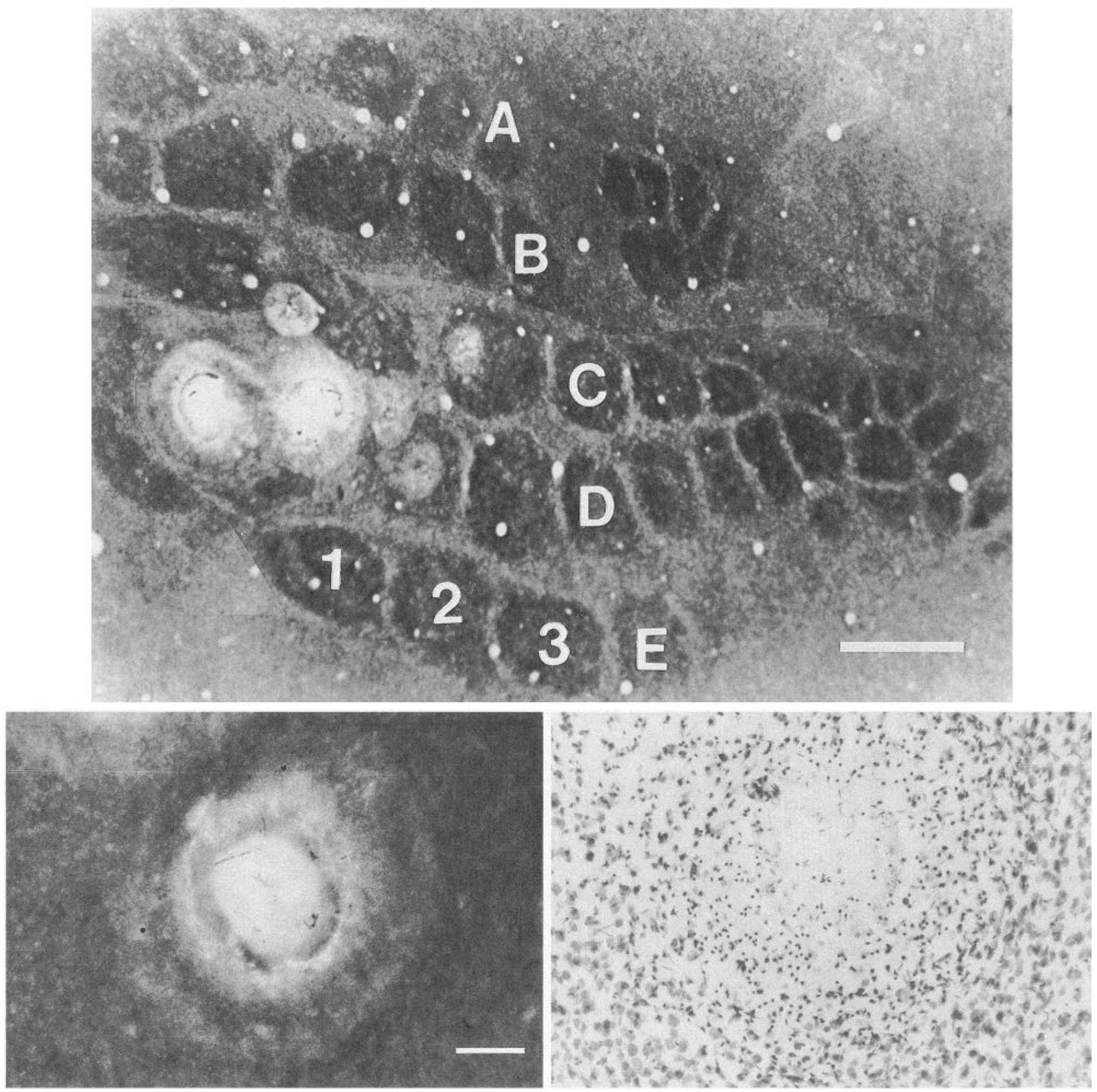

Figure 2. Top, Example of a lesion in the D1 barrel of a normally reared animal. In this animal, approximately $80 \%$ of the barrel volume was destroyed by two lesions, one of $16 \mu \mathrm{A} \mathrm{DC}$ and one of $24 \mu \mathrm{A} \mathrm{DC}$ applied for $10 \mathrm{sec}$, tip negative, placed at $600 \mu \mathrm{m}$ below the pia. The small lesions surrounding the two main lesions mark the recording locations of microelectrode penetrations made to assay the effect of ablating the D1 barrel. The barrels are stained for cytochrome oxidase. Section thickness, $60 \mu \mathrm{m}$. Bottom left, A higher-power view of a barrel lesion in tissue stained for cytochrome oxidase. Bottom right, An adjacent section stained for Nissl substance. Note the correspondence between the cell-sparse region at bottom right panel and the pale halo in bottom left panel. Scale bars: top $500 \mu \mathrm{m}$; bottom left and right, $200 \mu \mathrm{m}$.

D1, 1 a response to D1 and no response to the principal vibrissa, and 0.5 equal input from the two. For ratios of principal to D1 response between $0.1: 1$ and $9: 1$ the function is relatively linear. The $F$ values are plotted as vibrissa dominance histograms for different data sets in the Results.

\section{Results}

Normally reared animals

To determine whether the D1 barrel is the main source of horizontally spread D1 vibrissa excitation, we recorded neuronal responses to stimulation of the D1 vibrissa in barrels surrounding D1, having first ablated the D1 barrel with microlesions (see
Materials and Methods). Recordings were made from 59 cells in 12 penetrations in four normally reared adult animals with lesions of the D1 barrel, beginning 1-2 hr after making the lesion. These are compared with the responses of 126 cells recorded in normally reared animals without lesions of the D1 barrel.

\section{Lesions}

An example of a lesion that encompasses almost all of the D1 barrel is shown in Figure 2. The border of the lesion was taken as the limit of the pale cytochrome oxidase-deficient "halo" 


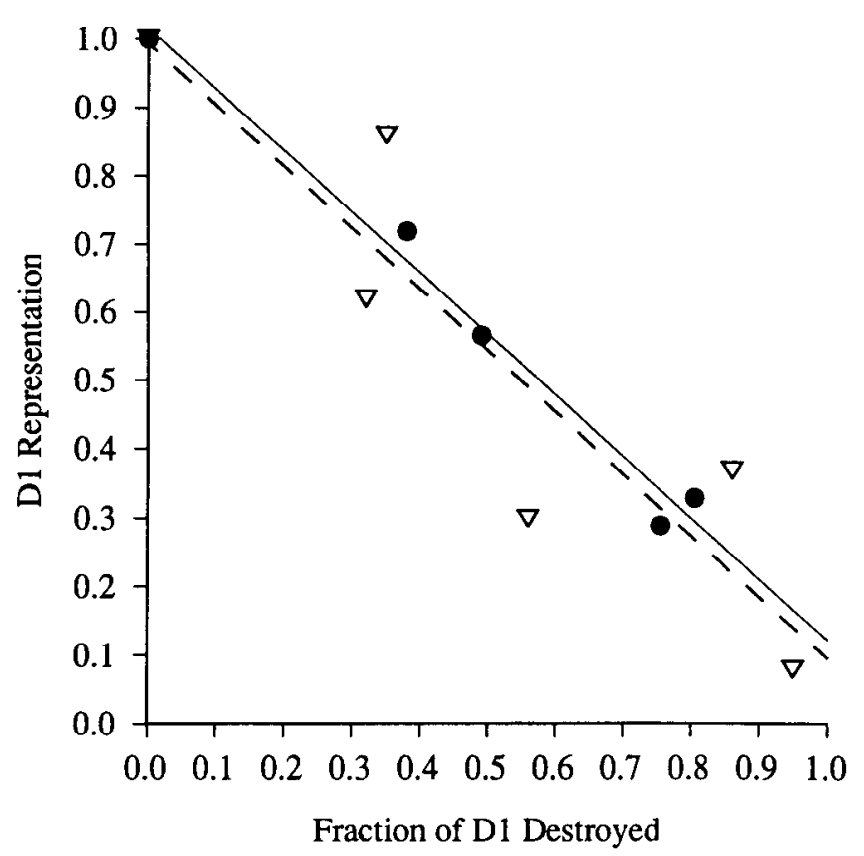

Figure 3. Relationship between damage to a barrel and loss of the corresponding vibrissa's input into neighboring barrels in normally reared animals. The D1 representation in barrels surrounding D1 (see Materials and Methods for definition) is plotted for four normally reared animals with lesions of the D1 barrel (๑). Larger lesions cause a greater reduction in response to D1 stimulation surrounding cortex. The D1 representation is also included for 126 cells averaged from 37 penetrations in animals without lesions (fraction destroyed $=0$ ). The data have been normalized for the D1 representation to be unity for the case where no lesion was made. The points are closely fitted by a straight line $(y=$ $\left.1.01-0.89 x, r^{2}=0.98\right)$. Data are also included from Armstrong-James et al. (1991a, $\nabla)$, normalized so that the control value from that study (D1/P $=0.37$, calculated from their Table 2) is superimposed on the control value from this study $(\mathrm{D} 1 / \mathrm{P}=0.31)$. The best straight line fit for that data is also good $\left(r^{2}=0.83\right)$ and matches closely the straight line fit for data from this study.

surrounding the lesion cavity (see Fig. 2 and Materials and Methods). Barrel lesions measured between 10 and $41 \mathrm{nl}$ in layer IV, and destroyed $38-80 \%$ of the volume of the DI barrel. Lesions were not restricted to layer IV and in all cases encroached on cells at the layer III/IV border and lower layer III to some extent. In coronal section the lesions were pear shaped with the base in layer IV and the stem reaching up into layer III. The lesion volume ranged between $10.9 \%$ and $23 \%$ of the D1 column in layers II/III. Lesions encroached very little on the surrounding barrels ( $0-3 \%$ of surrounding barrel volume).

\section{Response properties}

The effect of the lesions can be seen in Figure 3, where the size of the lesion is plotted against the strength of neuronal response to D1 vibrissa stimulation for cells recorded in barrels surrounding D1. The strength of response is calculated as the response to D1 stimulation, in spikes per stimulus, averaged over all the cells in the sample for a particular animal and normalized to the average principal vibrissa response (see Materials and Methods). In animals without lesions, the average D1 response was 0.43 and to stimulation of the principal vibrissa 1.38 spikes per stimulus. The ratio between the two (of 0.31 ) is represented as $100 \%$ in Figure 3. There were two main reasons for normalizing the average $\mathrm{D} 1$ response to the average principal vibrissa response: first, for ease of comparison with a previous

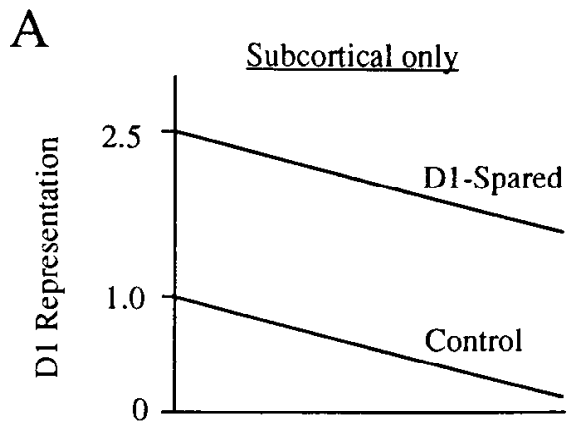

B
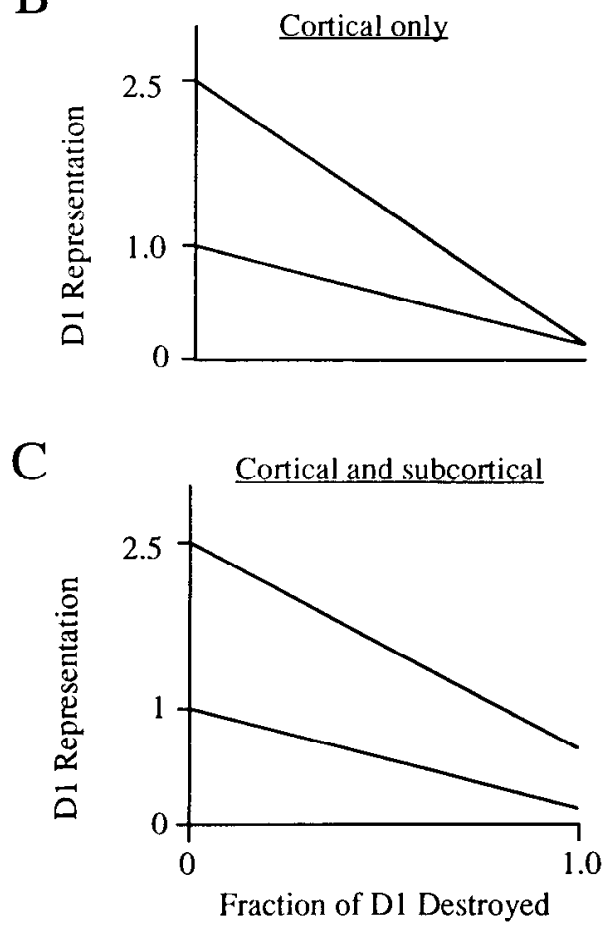

Figure 4. Three possible outcomes of univibrissa rearing. The graph showing the relationship between D1 lesion size and D1 representation for normal animals in Figure 3 could change in one of three ways. $A$, If subcortical divergence is the only factor to change, the D1-spared animals should show no greater decrease in D1 response with increasing lesion size than controls. In this case, a complete lesion of D1 should leave D1 responses considerably higher in D1-spared animals than controls. $B$, If cortical divergence is the only factor to change, lesions of the D1 barrel should have a greater effect on the D1 representation in univibrissa animals than in controls, and a complete lesion of D1 should reduce the D1 responses to the same levels as a complete lesion of D1 does in controls (about 12\% of normal). $C$, If both subcortical and cortical plasticity occur, a hybrid of $A$ and $B$ would be predicted, where both the intercept with the $100 \%$ lesion line and the slope would be increased.

study (Armstrong-James et al., 1991a), and second to account for nonspecific excitability differences between animals. The average D1 response, relative to the principal vibrissa response, can be seen to decrease as the volume of D1 destroyed by the lesion is increased. The data are fitted closely by a simple linear plot (solid line; coefficient of determination $r^{2}=0.98$ ). The results are in close correspondence with those reported in a recent independently conducted study (dashed line, Fig. 3). Taken together, these results strongly suggest that neurons in the D1 barrel relay D1 vibrissa excitation to cells in neighboring barrels. The extrapolation of the data to the case where the entire D1 


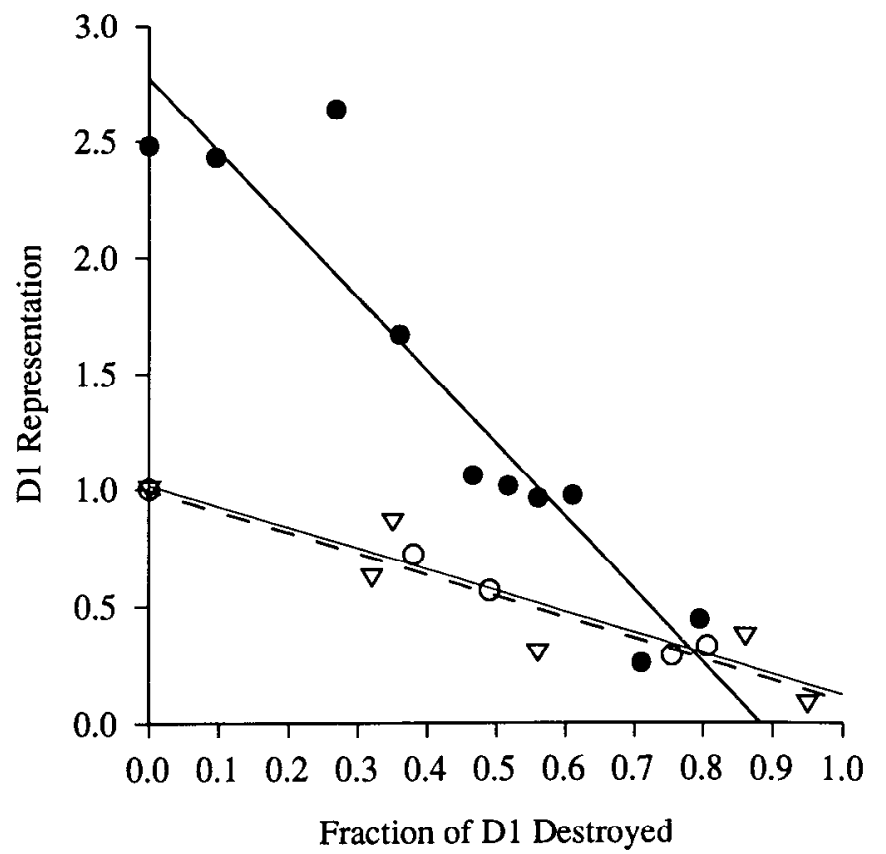

Figure 5. The relationship between damage to the D1 barrel and representation of the D1 vibrissa in barrels surrounding D1. Results are plotted for nine univibrissa animals sustaining acute lesions of various sizes to the D1 barrel ( $(0)$. The straight line fit of the data from Figure 3 is included for comparison. The results for the deprived animals are fit reasonably well by a straight line $\left(y=2.77-3.14 x, r^{2}=0.88\right)$. The plot is similar to Figure $4 B$ and suggests only cortical plasticity has occurred.

barrel is ablated predicts a small D1 representation in barrels surrounding D1 of $10-12 \%$ of normal levels. This residue presumably represents the presence of a small subcortical divergence of D1 excitation that is transferred to the cortex in normally reared animals.

Since the plot of lesion size versus D1 representation is fitted closely by a straight line, the strength of the responses to D1 vibrissa stimulation in barrels surrounding D1 would appear to be directly proportional to the number of $\mathrm{D} 1$ barrel neurons. The slope of the curve therefore reflects the strength of D1 excitation in surrounding barrel territory per D1 barrel neuron, that is, the projected excitation per number of source barrel neurons. Therefore, the slope should give a measure of the strength of the intracortical component of plasticity (Fig. $4 B$ ). As mentioned above, the curve fit for normal animals predicts that a total lesion of the D1 barrel would still leave $10-12 \%$ of the original D1 representation intact (Fig. 3), due to the fact that some subcortical divergence of D1 information occurs in normal animals. If increased subcortical divergence were to occur, then the intercept of the curve with the $100 \%$ lesion line should also increase (Fig. 4A). A combination of the two is also possible and should allow one to recognize the condition where cortical and subcortical plasticity occur together (Fig. 4C).

\section{Univibrissa animals}

To determine which, if any, of the possibilities outlined in Figure 4 apply to univibrissa animals, we recorded neuronal responses to D1 vibrissa stimulation in barrels surrounding D1, having first ablated the D1 barrel with microlesions. Recordings were made from 128 cells in 44 penetrations from nine animals with lesions, beginning $1-2 \mathrm{hr}$ postlesion. These are compared with

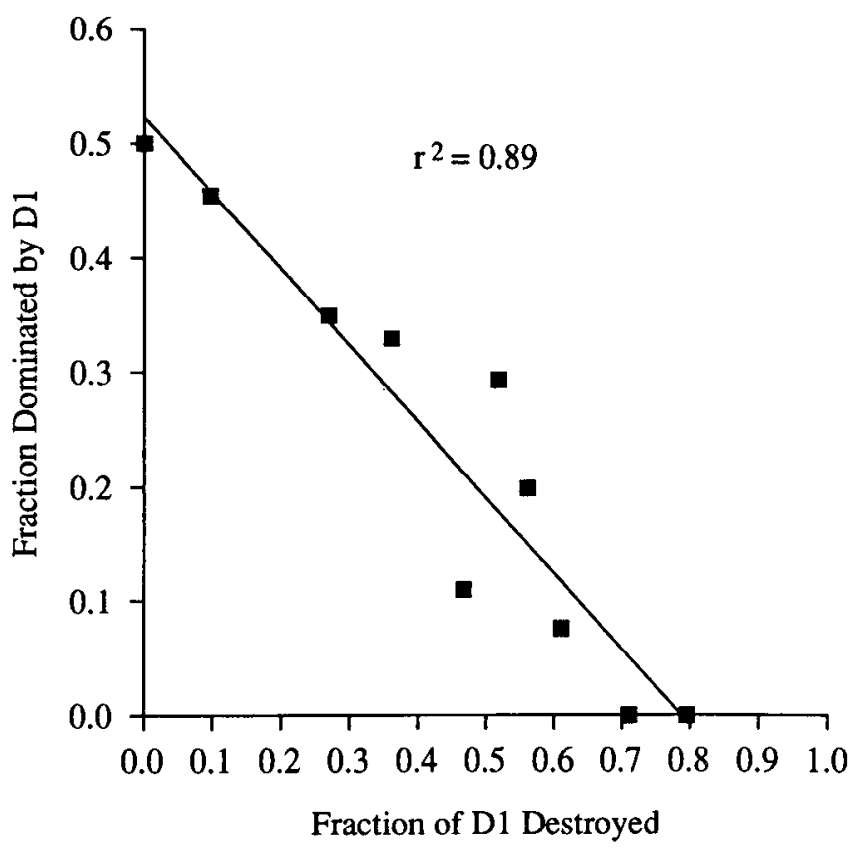

Figure 6. The effect of damage of the D1 barrel on vibrissa dominance. The percentage of cells showing a greater response to D1 stimulation than to principal vibrissa stimulation in barrels surrounding D1 are plotted versus the fraction of D1 damaged by the lesion.

the vibrissa responses of 159 cells recorded from seven univibrissa animals without lesions.

\section{Lesions}

Barrel lesions ranged in size from 14 to $68 \mathrm{nl}$ in layer IV. Lesions damaged between $9.6 \%$ and $80.5 \%$ of the D1 barrel in different animals. Some of the lesion extended out of layer IV toward the surface of the cortex, damaging between 8.4 and $23.9 \%$ of the D1 column in layers II/III in seven of the cases and $41 \%$ in the other two. However, the lesions were relatively restricted to layers II/III and IV and not more than $5 \%$ of the lesion encroached on layer $\mathrm{V}$ in any of the cases. Barrels surrounding D1 were not greatly damaged by the lesions, which lost just $2-4 \%$ of their barrel tissue, except in the case of one lesion where $23 \%$ of D2 was destroyed.

\section{Response properties}

The effects produced by the lesions are shown in Figure 5. The data have been analyzed in exactly the same way as described above for the normally reared animals (Fig. 3), which are included for comparison. The linear fit to the data for univibrissa animals is reasonably good $\left(r^{2}=0.88\right)$ and most resembles the theoretical curve Figure $4 B$, implying that plasticity is accounted for by cortical changes and that no relay of subcortical changes is necessary to explain the data. The decrease in strength of the D1 input to surrounding barrels was mirrored by a decrease in the number of cells dominated by the D1 vibrissa. Figure 6 shows that the percentage of cells dominated by D1 decreases approximately linearly $\left(r^{2}=0.89\right)$ from an initial prelesion value of $50 \%$ to $0 \%$ when the lesion encompassed $70-80 \%$ of the D1 barrel volume. In this sense, the largest cortical lesions appear to abolish plasticity completely.

The detailed analysis of the effects of the lesions can be seen in Figure 7. The number of cells dominated by D1 falls to zero 
when the lesion size reduces the average D1 response to the same value expected in a normal animal with a comparable lesion (Fig. 7A). The average D1 response does not vary significantly for cases where the D1 lesions are small, resulting in a plateau region in the plot. Only when the lesion size exceeds about $40 \%$ is there a large decrement in the cells' responses to D1 stimulation.

The average principal vibrissa response increases slightly as the size of the D1 barrel lesion increases. In the original formulation of the hypothesis the average principal vibrissa response was assumed to be independent of the D1 lesion size and therefore a means of normalizing the data for general nonspecific differences in excitability between different animals. However, this assumption appears not to be valid, as the principal vibrissa representation increases with lesion size; this increases the slope of the graph in Figure 5 beyond that predicted in Figure 4. A comparison of the control principal vibrissa representation (Fig. 7, triangles) with those for small lesions, or no lesions at all, in the univibrissa animals suggests that the responses to the deprived principal vibrissae are smaller in univibrissa animals. The principal vibrissa responses jump to normal values for lesion sizes greater than about $40 \%$, implying that active cortical suppression induced by univibrissa rearing has been unmasked. Therefore, barrel ablation of around $40 \%$ appears to form a threshold above which both principal and D1 vibrissa representations are altered and below which they remain approximately constant.

\section{Specificity of the lesion}

The location of the lesion within the barrel field was found to influence the decrement in response to D1 stimulation more than the absolute size of the lesion. This point is illustrated in Figure 8, where the absolute size of the lesions in layers II/III and IV is plotted against the strength of D1 response in surrounding barrels. In both cases, the correlation between the size of the lesion and the D1 representation is at low levels $\left(r^{2}=\right.$ 0.25 for layers II/III and for layer IV). For example, a lesion volume of approximately $21 \mathrm{nl}$ in layer IV occurred on five occasions, resulting in very different D1 representations, ranging from 0.26 to 1.7 , that is, $68 \%$ of the total range. However, the same values of D1 representation plotted against the volume of D1 destroyed in layer IV, or the volume of the D1 column destroyed in layers II and III, showed a close correlation between the two $\left(r^{2}=0.53\right.$ for layer II/III and 0.88 for layer IV). Therefore, the size of the lesion was far less critical for determining D1 responsiveness than whether or not it encroached on the D1 barrel. Because nonspecific damage of the cortex increases with lesion size, the lack of correlation between absolute lesion size and the strength of the D1 response strongly suggests that the larger lesions did not cause a decrease in D1 response by producing more overall cortical damage.

The fact that only responses to D1 vibrissa stimulation were decreased by the lesions also shows that the lesions had a specific effect. The average principal vibrissa response was relatively constant at 1.1-1.7 spikes per stimulus per neuron over a range of D1 lesions destroying between $40 \%$ and $80 \%$ of the D1 barrel. These figures are similar to the range of principal vibrissa responses found in normal animals (1.2-1.4 spikes per stimulus per neuron). Again, this suggests that the lesions were not affecting responses to D1 stimulation by causing a general decrease in cortical responsiveness. The principal vibrissa response was slightly smaller than normal for lesions of less than $40 \%$ of the

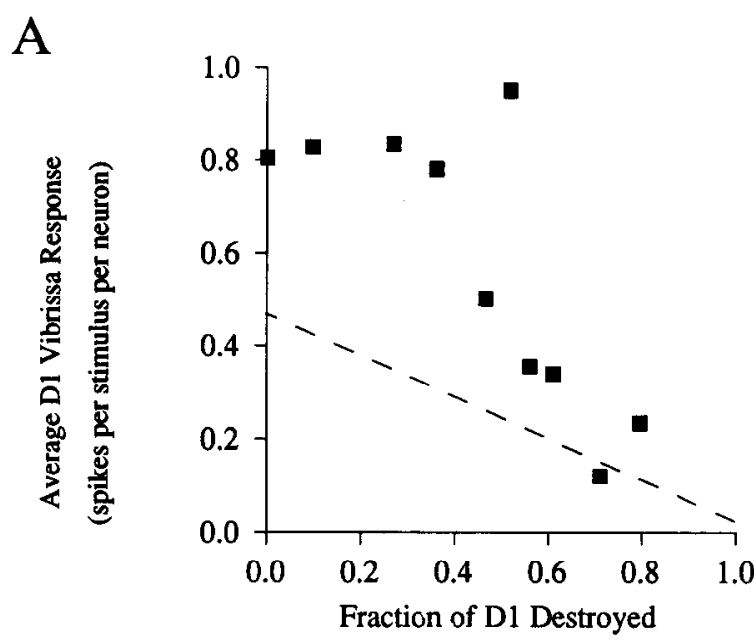

B

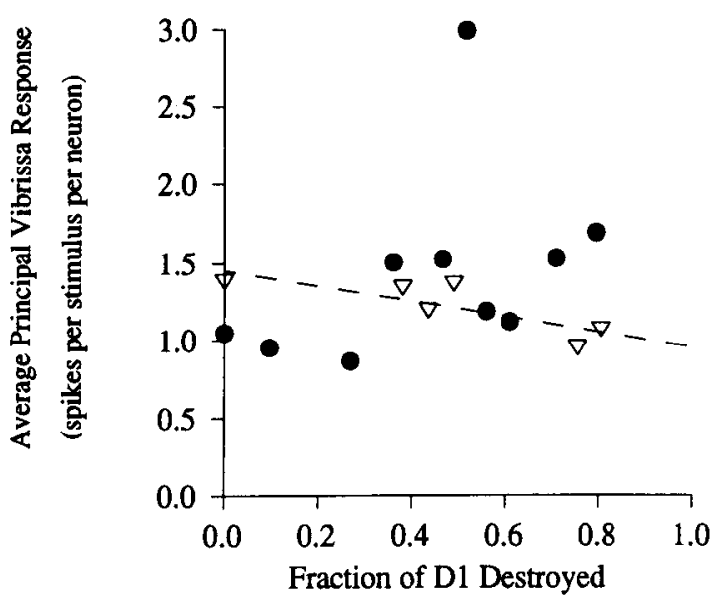

Figure 7. The relationship between damage to the Dl barrel and the average D1 principal vibrissa response in barrels surrounding D1. The same animals described in Figure 5 are plotted showing the average D1 response magnitude $(\mathbf{Q}, A)$ and the average principal vibrissa response magnitude $(-B)$. The dashed line in each case represents the best straight line fit for control data. In $B$, triangles represent control data points.

D1 barrel, so, far from decreasing principal vibrissa responses due to nonspecific damage, D1 barrel lesions actually increased principal vibrissa responses slightly.

\section{The effect of lesions aimed at the septum on vibrissa} dominance

To understand which intracortical pathways are involved in experience-dependent plasticity, rows of lesions were made in the cortex of univibrissa animals aimed at severing any connection running outward from the D1 barrel into neighboring barrels. An example of such a lesion is shown in Figure 9. Here, the lesions are aimed at the septum between D1 and D2 and almost completely spare the D1 barrel neurons from damage. The small lesions around D2, E2, and C2 in this figure mark the position of recording penetrations made to assay the effect of the large lesions. Lesions were made in five animals and their position and extent are shown in Figure 10 for each case. In 
A

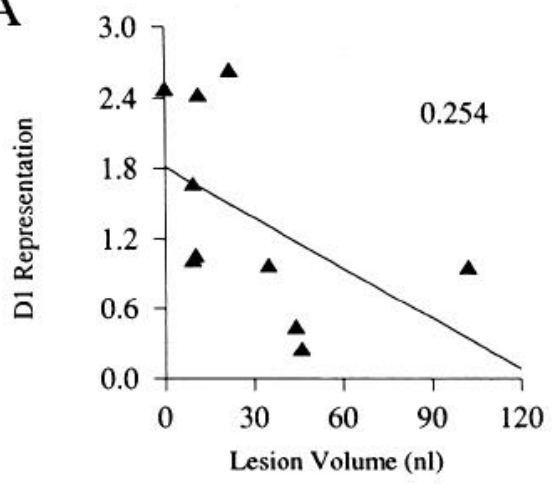

C

Figure 8 . The D1 representation is correlated with the amount of D1 destroyed, not the absolute size of the lesion. D1 representation is plotted against absolute lesion volume in layers II/III $(A)$ and layer IV $(C)$. Correlation between these parameters is low and $r^{2}$ values are shown in each respective graph. However, there is greater correspondence between the D1 representation in barrels surrounding D1 and the amount the lesion destroys of the layer II/III column above the D1 barrel $(B)$ and the amount of the D1 barrel destroyed $(D)$.

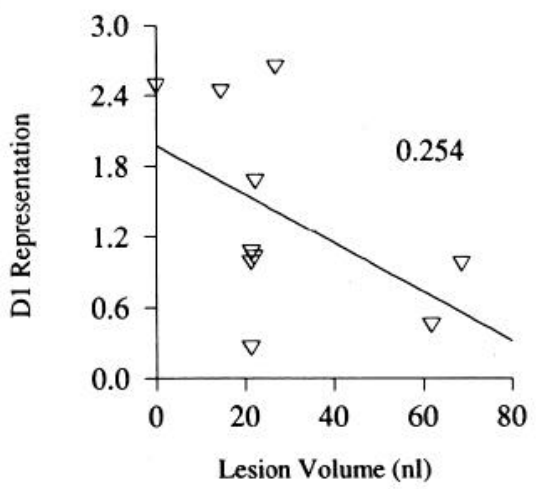

B

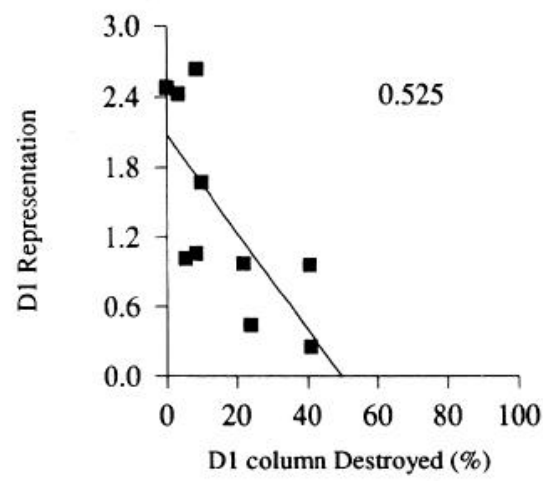

D

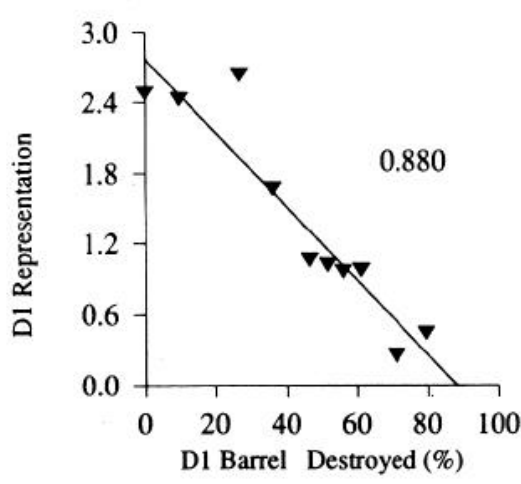

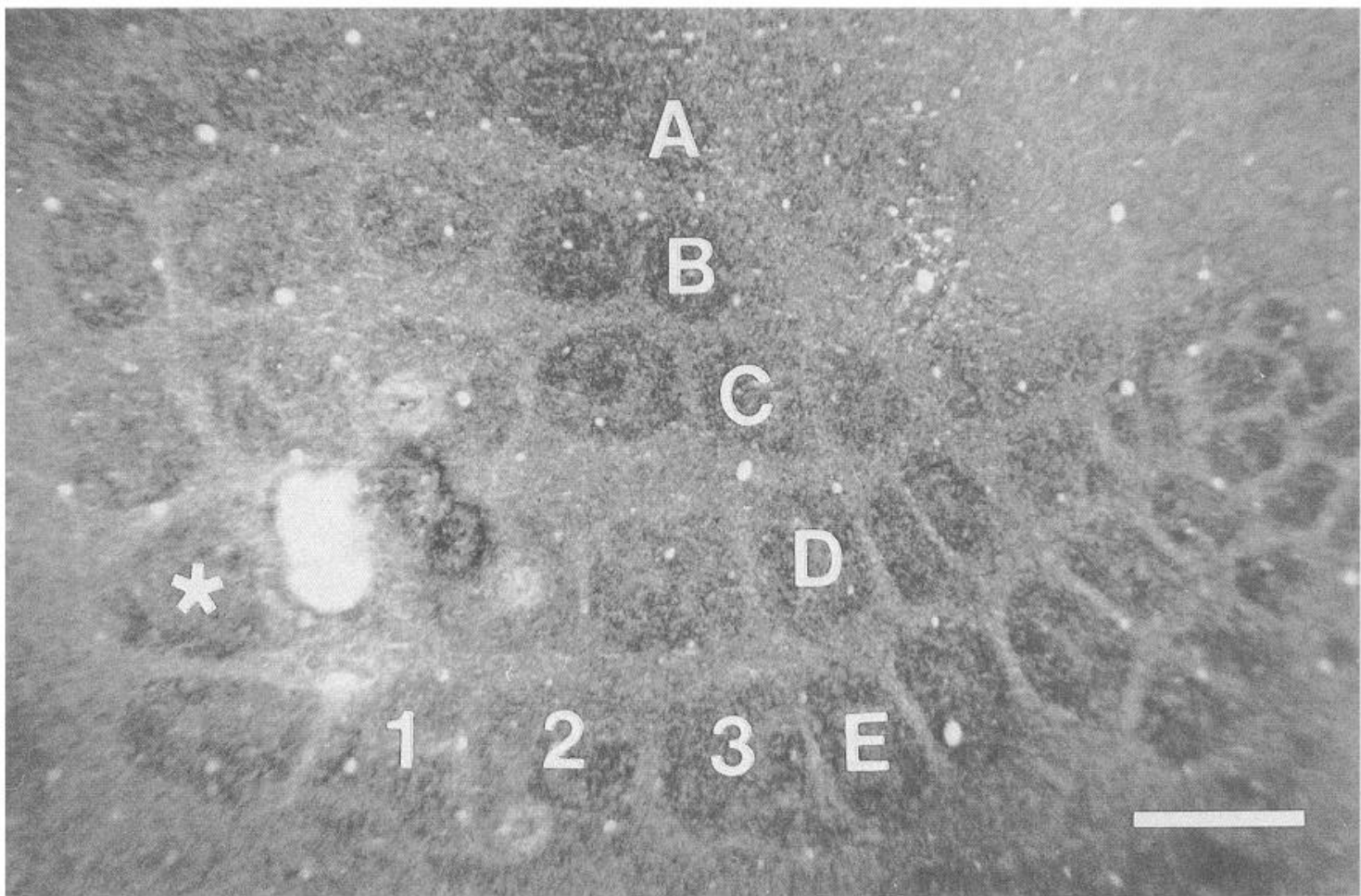

Figure 9. Example of a lesion dividing the D1 and D2 barrels along the layer IV septal region. This lesion destroyed $20 \%$ of the D1 barrel volume and extended into the lower half of layer III, destroying $2 \%$ of the layer II/III column. One $22 \mu \mathrm{A}$ and two $15 \mu \mathrm{A}$ lesions were made at depths of 650 and $600 \mu \mathrm{m}$, respectively (10 sec DC, tip negative). The small circular lesions in the D2 barrel mark the location of the recording penetrations. The D1 barrel is to the left of the lesion (confirmed from microelectrode recordings) and is marked with an asterisk. $\delta$ is directly below D1. Section thickness, $60 \mu \mathrm{m}$. Scale bar, $500 \mu \mathrm{m}$. 
A

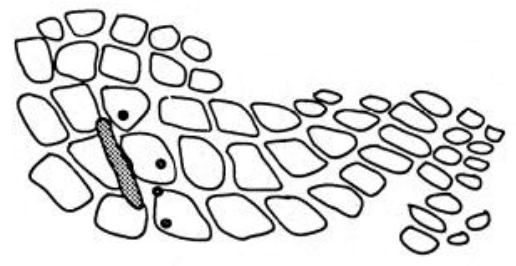

B

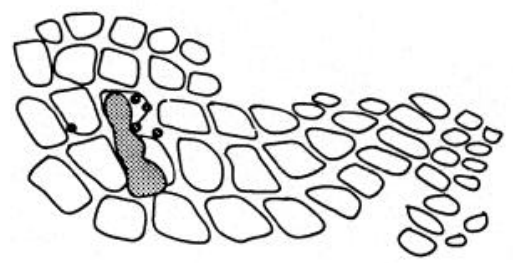

C

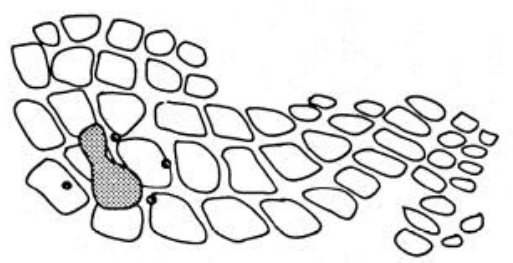

D

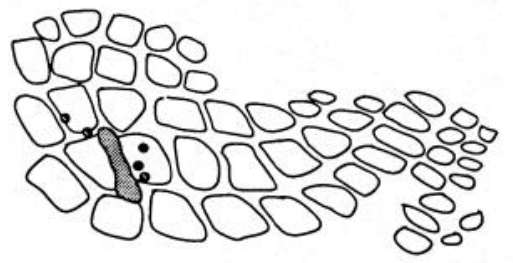

E

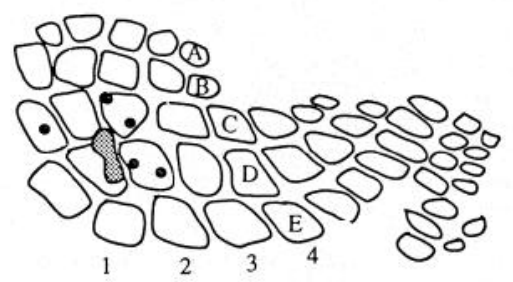

Figure 10. Five cases of lesions aimed at the septum are shown in diagrammatic form to summarize the scope and location of the lesions. The large shaded areas depict the border of the lesion within layer IV. The small shaded circles represent recording locations made starting 1$2 \mathrm{hr}$ after the main septal lesions.

total, 94 cells were recorded in 23 penetrations, beginning 1-2 hr after the lesion had been made.

\section{Lesions}

Rows of three lesions were used to cut the barrel field and varied in volume between 30 and $40 \mathrm{nl}$ in layer IV. With one exception (see Fig. 10C), the position of the lesions tended to spare most of the D1 barrel itself. Lesions destroyed between $0 \%$ and $30 \%$ of the volume of the D1 barrel for four of the cases and just $1.0-5.1 \%$ of the D1 column in layers II/III. In Figure $10 C, 46.8 \%$ of the D1 barrel and $23 \%$ of the D1 column in layers II/III were destroyed. In none of the cases did the lesion extend deeper than layer IV.

\section{Response properties}

In each case the D1 representation was reduced substantially in barrels cut off from the D1 barrel by the lesion. As can be seen from Figure 11, 76\% of cells showed no response to D1 in layers
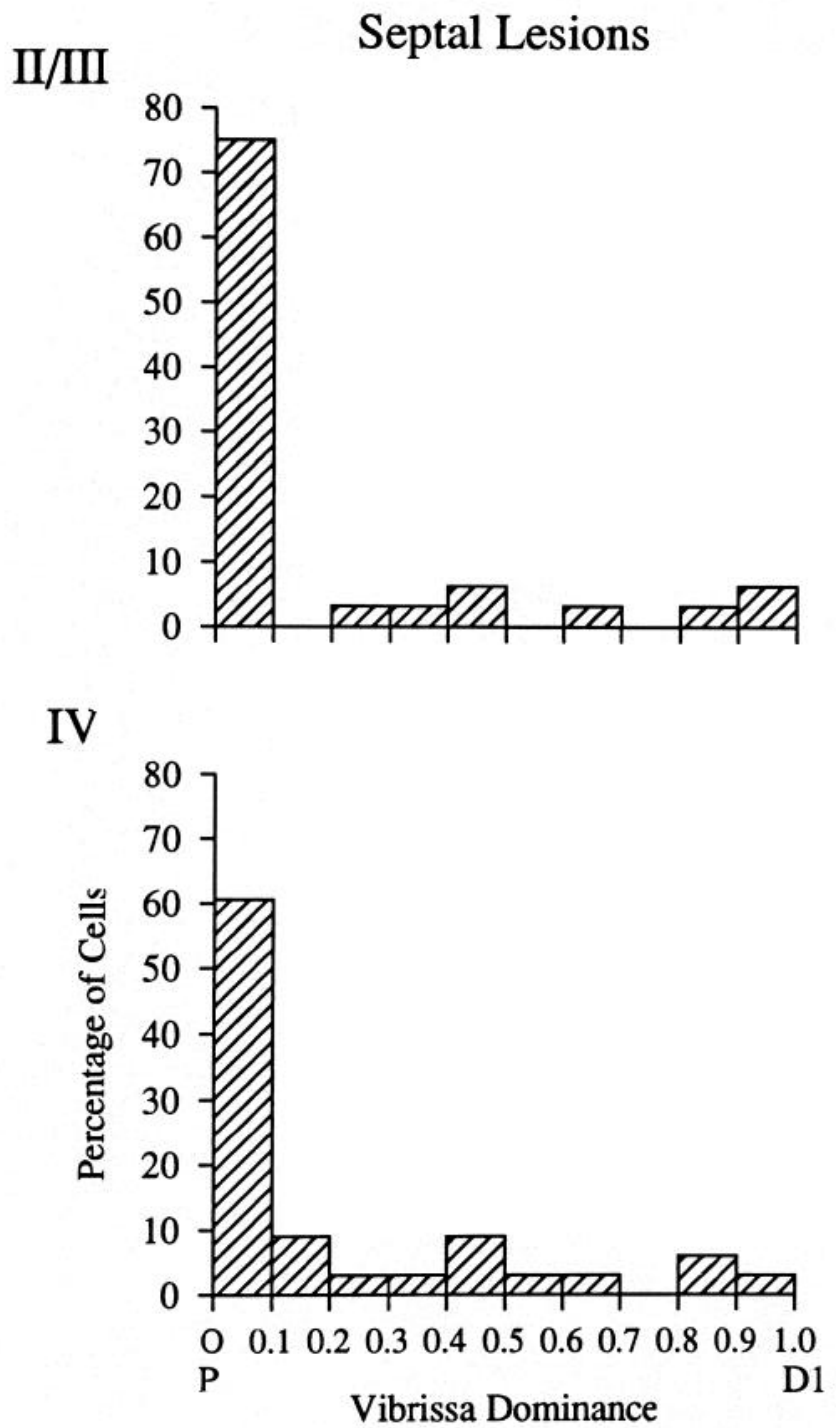

Figure 11. Rows of lesions dividing two barrels along the septum reduce D1 dominance. Data are shown for 27 layer II/III cells (top) and 38 layer IV cells (bottom) recorded in animals with lesions aimed at the septum. D1 dominance is affected more than for the spherical barrel lesion cases, but some cells still remain dominated by D1 despite the lesion. (The 29 cells deliberately recorded behind the row of lesions in unsevered barrels have not been included.)

II and III (compared with $11 \%$ in univibrissa animals without lesions) and $61 \%$ showed no response to D1 in layer IV (compared with $19 \%$ in univibrissa animals without lesions). The effect of severing the D1 barrel from its neighbor was to reduce the D1 responses in the univibrissa animals to less than observed in normally reared animals, with only $25 \%$ of the cells showing any response to D1 at all compared with $45 \%$ in normally reared animals. Four of five lesions reduced D1 responses in surrounding barrels with little damage to the D1 barrel. In the only case where substantial damage of the D1 barrel did occur $(46.8 \%$ in Fig. $10 C$ ), the reduction in D1 responses was actually smaller than for the other cases, presumably because a small island of the D1 barrel survived the lesion and was directly contiguous with the D2 barrel recording sites.

We reanalyzed the data from the nine animals that had received more spherical lesions to see whether the continuity of tissue between the recorded cell and the D1 barrel had influenced 


\section{II/III \\ Severed from DI}

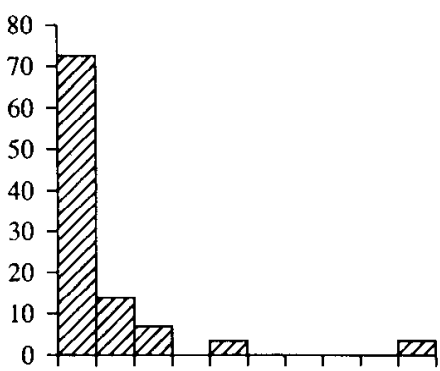

IV

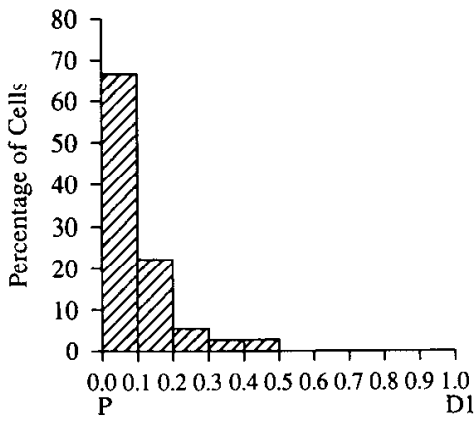

Connected to D1
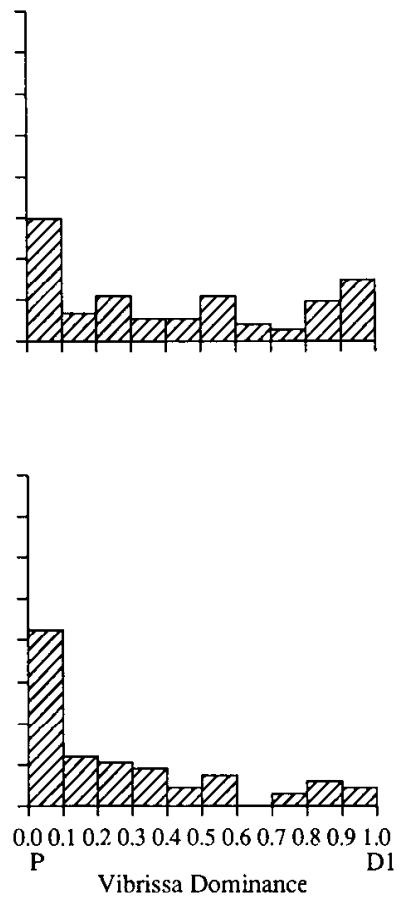

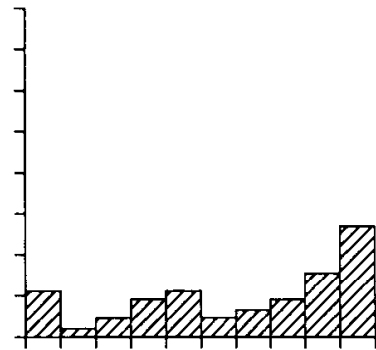

No Lesion

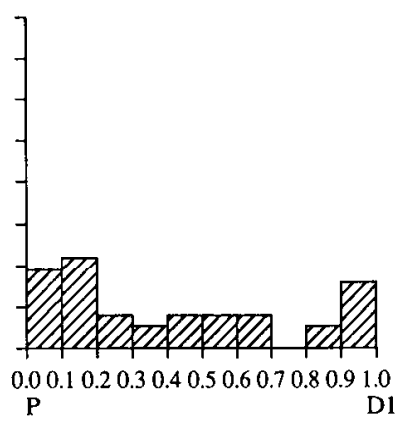

Figure 12. Neurons in penetrations severed from the D1 barrel by the lesion reduce D1 dominance to less than control levels. Data are combined from experiments with lesions aimed at barrels and septae and grouped by layer (top, layers II/III; bottom, layer IV) and by whether a direct line between the penetration and any point on the D1 barrel was interrupted by the lesion. Left column shows the distribution of $F$ values for cells severed from D1. These cells show less D1 influence than normally reared animals without lesions. Middle column. Data from the same animals described by the left histograms, but recorded in penetrations that were still connected to D1 by neuropil. These cases show reduced D1 dominance compared with unablated animals (right histograms), but many cells dominated by D1 still remain.

Figure 13. Poststimulus time histograms (PSTHs) for responses to principal and D1 vibrissa stimulation. These histograms are examples of the responses of eight cells (recorded at the depths indicated) in two penetrations, one penetration severed from the DI barrel by the lesion (left) and one still connected to DI (right). There are no responses to $\mathrm{D} 1$ in the severed barrel (D2), but clear responses in the cells in the connected barrel (located in $\mathrm{Cl}$ ) where $D 1$ dominates the receptive field. All data recorded in the same animal within 50 min of one another. Bin width, $1 \mathrm{msec}$; PSTHs for 50 stimuli.
Severed from D1

D1
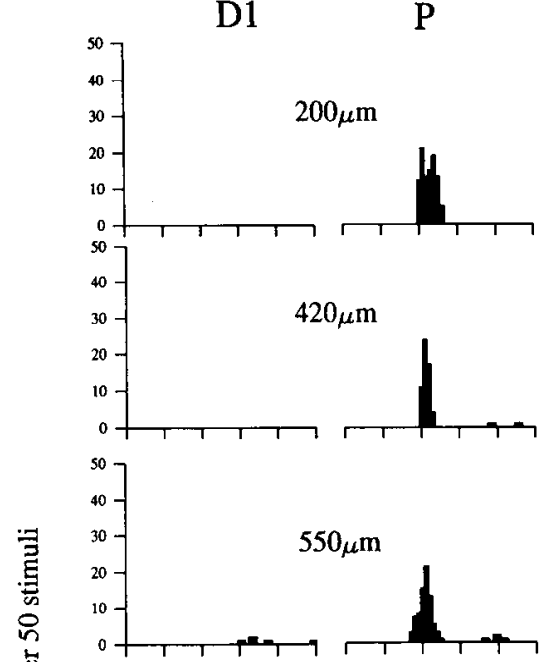

密

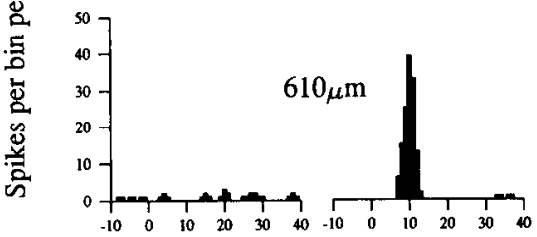

Time peristimulus (msecs)
Connected to D1

D1 $\quad \mathbf{P}$
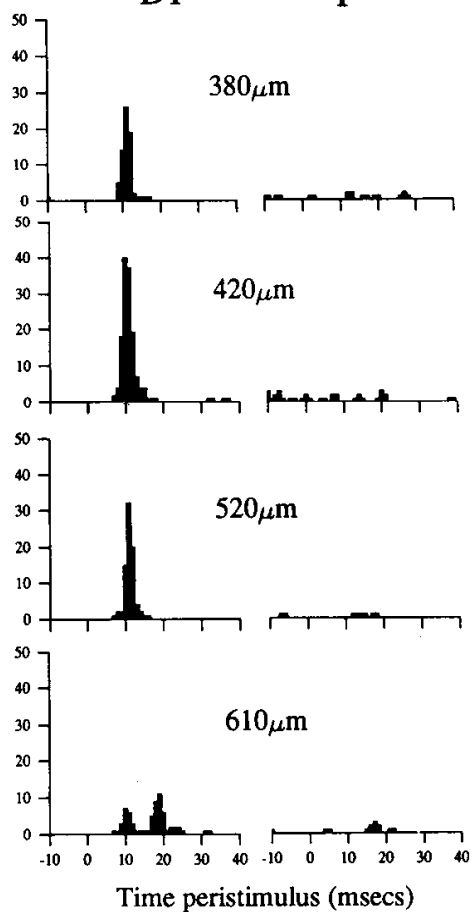
Severed from D1.

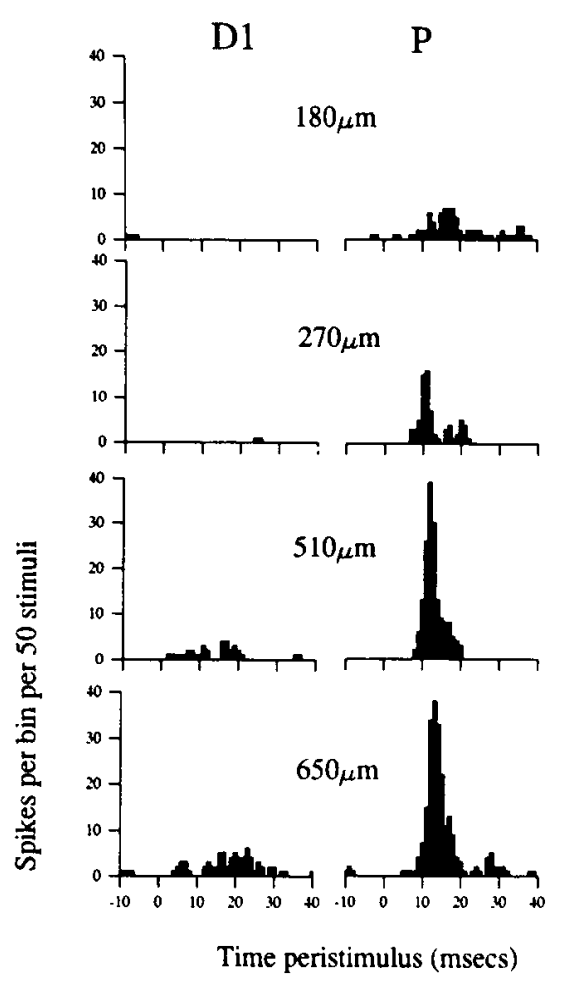

Connected to D1

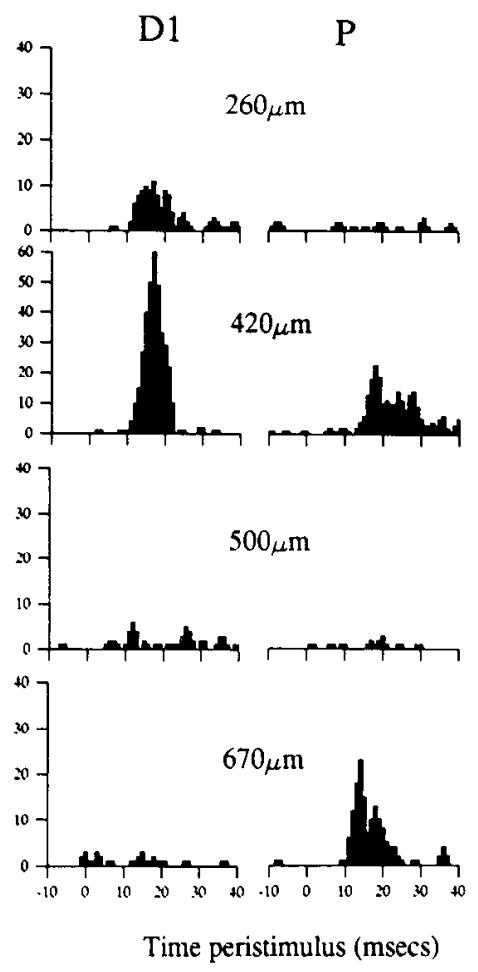

Figure 14. Poststimulus time histograms for responses to principal and D1 vibrissa stimulation. These are examples for eight cells (recorded at the depths indicated) in two penetrations, one severed from the D1 barrel by the lesion (left) and one still connected to D1 (right). In the severed barrel (E2), responses to D1 stimulation are absent in superficial layers and weak in layer IV. In contrast, the penetration in the connected barrel $(\gamma)$ shows stronger D1 than principal vibrissa responses in superficial layers. In layer IV the response of one cell was still dominated by the principal vibrissa. All data recorded in the same animal. Bin width, $1 \mathrm{msec}$; PSTHS for 50 stimuli.
D1 responsiveness in those cases also. The results are shown in the vibrissa dominance histograms of Figure 12. The position of the lesion clearly had a large influence on the outcome in these animals, too. All of the cells that exhibited D1 dominance were located in barrels still connected to the D1 barrel by a direct bridge of intact neuropil. As found before, cells that had been severed from D1 had smaller D1 responses than cells in univibrissa animals without lesions, or even than cells recorded in normally reared animals. Apparently, this did not mean that the only attribute of the spherical lesions to influence D1 responsiveness was whether they had severed the D1 barrel from the recording site, since the cells that remained linked to D1 despite the lesion still showed smaller and fewer D1 responses, on average, than those in animals without lesions, as shown in Figure 12 (middle histograms). The distributions are signiticantly different for both layer II/III $(p<0.002)$ and layer IV cells $(p<0.004)$, comparing neurons recorded in animals without lesions (histograms on right in Fig. 12) with neurons recorded in penetrations connected to the D1 barrel in animals sustaining D1 lesions (two-tailed Mann-Whitney $U$ test for large samples).

Having discovered that D1 responses could be abolished in one part of cortex while they were merely reduced in another, an effort was made in most experiments to record at least one penetration around the back of the row of lesions (Fig. 10B-E). This allowed us to verify that the animal in question had indeed undergone plasticity, and also provided an internal control against nonspecific damage of the barrel field. In each of the four cases, the neurons in the unsevered barrels exhibited the large D1 dominance usually found in these univibrissa animals, implying that plasticity had occurred. In total, $65 \%$ of the cells responded more to $\mathrm{Dl}$ than they did to the principal vibrissa, which is a slightly higher rate of occurrence than found in univibrissa animals with no lesions. Two of the four penetrations are shown in Figures 13 and 14, and represent examples of the difference between recording in a position severed from the D1 barrel compared with an unsevered location. Figure 13 shows an extreme example, where only principal vibrissa responses remain in the Dl severed case (left column), whereas the cell recorded in an adjacent barrel, still joined by neuropil to D1, showed only D1 responses. Figure 14 shows a moderate example, where a small vestige of a D1 response remains in layer IV, despite the lesion, and D1 dominance is greater in layers II/III than in layer IV in the unsevered case, illustrating an earlier finding that plasticity is greater in superficial layers at all ages (Fox, 1992).

\section{Response latencies in layer IV}

The effect of the cortical lesions on fast $(5-10 \mathrm{msec})$ responses to D1 stimulation were of particular interest, as they probably represent the action of direct monosynaptic connections from the thalamus onto layer IV cells. In univibrissa animals without lesions, approximately $30 \%$ of the layer IV cells in barrels surrounding D1 respond within $10 \mathrm{msec}$ to stimulation of the D1 vibrissa (Fox, 1992). On average, this value falls to approximately $20 \%$ ( 20 of 102) in animals with lesions of the D1 barrel, implying that short-latency responses are affected by cortical lesions. However, all of the fast responses discovered after the lesions had been made were located in penetrations that had not been severed directly from the DI barrel. If such penetrations are considered on their own, the percentage of fast responses in such tracks is identical to that found in normally reared animals without lesions $(30.3 \%, 20$ of 66$)$. Conversely, none of the cells recorded in penetration severed from D1 showed any fast responses $(0 \%, 0$ of 36$)$. This implies that fast responses 
are essentially unaffected by the lesion unless it severs a direct link from the D1 barrel to a cell located in surrounding cortex (see Discussion).

\section{Discussion}

It was found that lesions of the D1 barrel reduce significantly responses to stimulation of the D1 vibrissa in barrels surrounding D1 (when lesions destroy in excess of about $40 \%$ of the D1 barrel). In addition, lesions aimed at the septum between D1 and an adjacent barrel almost completely abolished responses to D1 vibrissa stimulation, but only at locations directly severed from Dl; any cell recorded in barrels remaining contiguous with D1 exhibited unattenuated responses to D1 stimulation. These results imply that barrel lesions reduce $\mathrm{D} 1$ vibrissa excitation to surrounding cortex partly by decreasing the number of projection neurons in the D1 barrel and partly by severing pathways leading out of the D1 column, through layer IV or II/III or both.

The experiments reported here were effectively conducted blind; the exact position of the recording penetration relative to the lesion and the D1 barrel were critical determinants of whether or not a cell responded to D1 stimulation, yet these factors were discovered only after the electrophysiological recording had been completed and the histology analyzed. In practice, it proved difficult to adjust the lesion until it severed every recorded cell from the D1 barrel, and therefore many cells were inadvertently recorded in penetrations contiguous with the D1 barrel. These unintentional controls proved useful for a number of reasons. (1) They prompted reanalysis of the earlier experiments with spherical lesions, leading to the finding that, in these cases, too, a bridge of neuropil connecting D1 to the recorded cell was essential if the neurons in that penetration were to maintain their potentiated D1 responses. (2) They showed that the lesions were very specific in their effect, since cells in nearby penetrations at similar distances from the lesion showed very different levels of response to $\mathrm{D} 1$ dependent on their connection with the D1 barrel. (3) They showed that the initial degree of plasticity expressed by individual animals was at its usual high levels in some parts of the cortex, since cells in unsevered barrels exhibited DI-dominated receptive fields (see Results).

It is possible to infer that the cortical microlesions used in these experiments abolished plasticity induced early in development, rather than at a later time period during deprivation, because the magnitude of plasticity observed in the unsevered barrels of these animals can be produced only by deprivations initiated before P4. If deprivation is started on P0, for example, $30 \%$ of the cells in layer IV exhibit aberrant short-latency responses to D1 stimulation, compared with $13 \%$ if started at P4 and $0 \%$ at P56. In the present subjects, $30 \%$ of the cells in unsevered barrels showed aberrant short-latency responses, implying that these changes were induced before P4. Similarly, deprivations initiated on $\mathrm{P} 0$ result in $37 \%$ of the layer IV cells exhibiting a greater magnitude response to Dl than to their principal vibrissa, compared with $12 \%$ when started at P4. In the present experiments, $21 \%$ of the cells in layer IV responded more to D1 than to the principal vibrissa, again implying that the effects were induced earlier than P4. The cortical microlesions therefore affected developmentally induced plasticity.

\section{The locus of plasticity (locus ductilis)}

The effects of lesions of the periphery on development of the somatosensory system are very different from the effects of altered tactile experience. For example, ablating vibrissa follicles at $\mathrm{P} 0$ prevents the corresponding barrels from forming in the cortex (Woolsey and Wann, 1976), whereas trimming or removing vibrissae starting on $\mathrm{P} 0$ allows all the barrels to form normally (Hand, 1982; Simons and Land, 1987; Fox, 1992). Similarly, ablating vibrissa follicles causes degeneration of peripheral nerves (Waite and Cragg, 1979), whereas careful and repeated removal of the vibrissae does not ( $\mathrm{Li}$ and Fox, unpublished observations). Because of the clear differences between the two paradigms, experience-dependent and lesion-induced plasticity are discussed separately below.

\section{Experience-dependent plasticity}

One of the main aims of this experiment was to test whether univibrissa rearing causes changes at synapses within the cortex itself. Previous experiments from this laboratory have distinguished between cortical and subcortical components for later ages of deprivation. Univibrissa rearing from about $\mathrm{P} 28$ onward causes plasticity in layer II/III cells in the absence of changes in layer IV, and therefore, since layer IV provides the main input to superficial layers, this result argues strongly that intracortical pathways are involved (Fox, 1992; Glasewski and Fox, 1994). For layer IV, it had been argued that changes in shortlatency responses of layer IV cells to vibrissa stimulation represent changes in the distribution of thalamocortical synapses brought about by univibrissa rearing (see Fox, 1992). However, the locus of plasticity was ambiguous still for the younger ages, particularly $\mathrm{P} 0-\mathrm{P} 2$, when the greatest changes can be produced in layer IV of the cortex. The present results, showing that lesions of the D1 barrel or of the neuropil linking D1 with its immediately surrounding barrels can abolish expression of plasticity in this system, suggest that intracortical pathways are changed by univibrissa rearing in the younger $\mathrm{P} 0$ animals, too.

Although the present results provide evidence for intracortical plasticity, they do not provide any evidence for the existence of a subcortical component to the plasticity measured in the cortex. If subcortical plasticity had occurred, for example, due to cells in the D2 thalamic barreloid increasing their responses to D1 stimulation, this novel pathway for routing D1 excitation should have survived lesions of the cortical D1 barrel in the same way that the pathway for routing D2 excitation survived (see Fig. 1). However, this was not the case, and only the D2 responses survived the D1 barrel lesion. Furthermore, lesions aimed at the septum between barrels drastically reduced D1 responses in the barrel cut off from D1, and yet such lesions are capable only of severing intracortical processes (possibly including thalamocortical axons). Therefore, either subcortical plasticity does not occur with univibrissa rearing or, if it does, the effects are not relayed to the cortex. In fact, univibrissa animals with near total deletion of the D1 barrel exhibited the same minor responses to D1 stimulation as normally reared animals with comparable lesions. Such residual responses are presumably due to normal subcortical divergence. This implies that the degree of subcortical divergence that affects receptive field size in the cortex is similar in normally reared and univibrissa reared animals.

The degree to which functional plasticity exhibited by one group of cells maps onto the target to which those cells project is generally not well understood. The evidence presented here suggests that even if thalamic plasticity occurs, it is not projected onto the cortex, perhaps due to the intrinsic response transformation that occurs in the thalamocortical link. For example, receptive field changes in the thalamus may be attenuated by 
intracortical inhibitory mechanisms. In any case, there is no evidence at present to suggest that experience-dependent plasticity does occur in the thalamus. Lesion-induced plasticity has been reported to occur in the thalamus (Garraghty and Kaas, 1991; Nicolelis et al., 1991), but the induction and expression mechanisms are quite different for lesion-induced and experience-dependent effects, as discussed below. There is some evidence that a subgroup of local circuit ncurons in the interpolaris subdivision of the spinal trigeminal nuclei can increase their receptive fields by one or two vibrissae in response to whisker trimming from birth (Jacquin et al., 1994). The net effect of these changes on the projection targets of nucleus interpolaris depends on whether the local circuit cells are inhibitory or excitatory, and this is not known at present. However, the interpolaris cells that project to the thalamus do not change receptive field size, which implies that the changes in local circuit neurons are not relayed in the interpolaris-thalamic projection. This again emphasizes that a structure exhibiting plasticity does not necessarily relay its plastic changes to its target.

\section{Lesion-induced plasticity}

Recent anatomical experiments have provided evidence that manipulations involving damage to the periphery can also cause changes in intracortical pathways; for example, infraorbital nerve section prevents intracortical axons from extending radially (McCasland et al., 1992). Furthermore, the well-studied changes in barrel morphology induced by follicle lesions (Woolsey and Wann, 1976) have also been shown to be due in part to cortical synaptic interactions (Schlaggar et al., 1993). Lesions of the C row vibrissa follicles that normally cause shrinkage of the $\mathrm{C}$ row barrels and expansion of the $B$ and $D$ rows are prevented by postsynaptic activity blockade. Therefore, there is evidence that lesion-induced and experience-dependent deprivations can cause changes in cortical connectivity, in layer IV during the first postnatal week, and in extragranular layers at later ages.

Lesion-induced plasticity has also been shown to occur subcortically in neonates. Lesion-induced plasticity occurs in primary afferents entering the trigeminal nuclei (Renehan et al., 1994) as well as the thalamus (Nicolelis et al., 1991). Lesioninduced plasticity has also been demonstrated in spinal cord (Basbaum and Wall, 1976) and thalamus (Garraghty and Kaas, 1992) of adults, making it difficult to ascribe functional changes in somatosensory cortex (Merzenich et al., 1983) exclusively to changes in intracortical mechanisms. However, it has also been argued that subcortical plasticity is unlikely to account for lesion-induced plasticity in area $3 \mathrm{~b}$ of the adult monkey, since area 1 receives similar thalamic projections but does not show plasticity (Wall et al., 1986). The problem of dissociating cortical from subcortical plasticity has been discussed elsewhere (Wall, 1988), but a few additional observations have been made since. It has been shown that digit amputation in the raccoon causes an increased cortical representation of the spared digits in the area of cortex deprived of its main digital input (Zarzecki et al., 1993). That this occurs in the absence of any change in the incidence of intracortical EPSPs suggests the effect is due to subcortical plasticity, or a change in the thalamocortical projection. In the rat vibrissa system, it has been found that deafferentation of all but one vibrissa in the neonate causes an expansion of the spared vibrissa representation at the trigeminal, thalamic, and cortical levels as revealed by the 2-DG technique (Liu et al., 1992). However, the greatest expansion occurs in the cortex, which could indicate that this is where the main plasticity occurs. In a different system, lesions of the retina have also been shown to alter intracortical connections in visual cortex of adults (Darien-Smith and Gilbert, 1994). In the cat somatosensory cortex, expansion of the spared digit representation does not occur if lesions of the basal forebrain deplete cortical $\mathrm{ACh}$ levels (Juliano et al., 1991). Since this nucleus is not known to innervate subcortical targets, this evidence suggests that the digit amputation causes mainly cortical effects.

The relative contribution of cortical and subcortical factors to lesion-induced changes measured in the somatosensory cortex therefore remains unresolved, though it seems clear that both cortical and subcortical pathways are affected. The present results indicate that the locus of experience-dependent plasticity is less complex to analyze since the changes that can be measured in the cortex are mainly, if not exclusively, due to cortical mechanisms.

\section{Comparing lesion-induced and experience-dependent plasticity}

In this study, the deprived input was found to have maintained some representation in the system despite the deprivation. Estimates of plasticity were taken as changes in the balance of responsiveness to the spared versus the deprived input. In lesion-induced plasticity experiments, comparison of spared and deprived input is obviously not possible if the pcriphcry is damaged, as it is no longer possible to stimulate the ablated receptors. In these cases, it is not known whether the representation of the deprived input expands, contracts, or remains constant. This complicates direct comparison of the effects of lesion-induced and experience-dependent plasticity.

Lesion-induced plasticity induces a complex series of changes in the peripheral nerves including nerve degeneration (Waite and Cragg, 1982), nerve regeneration to inappropriate peripheral targets (Rhoades et al., 1987), neuropeptide synthesis in ganglion cells (see Hokfeldt et al., 1994), reorganization of central terminations of primary afferents (Renehan et al., 1994), and, farther on in the somatosensory pathway, cell death $(\mathrm{Ha}-$ mori et al., 1882; Waite et al., 1992). If the integrity of the peripheral nerves are affected by the induction paradigm, it would seem almost inevitable that subcortical effects would be induced, as indeed they are (sce above). The induction mechanisms for lesion-induced plasticity are therefore very different from those of experience-dependent plasticity, where just the balance of activity transmitted in different pathways is altered. Evidence presented in this study implies that subcortical plasticity is not a major contributor to the plasticity observed in the cortex. As a general hypothesis, then, it is likely that delicate manipulations of the periphery, such as univibrissa rearing, cause plasticity only in the most sensitive areas of the somatosensory pathway, while more severe interventions, such as peripheral nerve lesions, cause plasticity in many areas of the somatosensory pathway. Implicit in this view is the idea that some cells have a lower threshold for plasticity than others. At present, it appears that cortical cells have low thresholds for plasticity. Plasticity thresholds vary even within the cortex itself as a function of age, and layers II and III show plasticity in the absence of changes in layer IV in older animals (Daw et al., 1992; Fox, 1992; Glazewski and Fox, 1994).

\section{Pathways for plasticity}

These studies raise the question of what pathways support plasticity in the cortex. In layer IV, aberrant short-latency responses to stimulation of the spared vibrissa are found in deprived bar- 
rels (Fox, 1992). These responses are the earliest evoked by vibrissa stimulation in the cortex and suggest a direct thalamocortical link is involved. It is possible that the morphological change underlying the wider dispersion of short-latency responses is due to altered development of stellate cell dendrites. Dendrites normally turn inward to face their own appropriate barrel unless the animal is subjected to a follicle or 6-OHDA lesion (Harris and Woolsey, 1981; Loeb et al., 1987). If univibrissa rearing were to cause stellate cell dendrites in deprived barrels to radiate more symmetrically, their dendrites could reach the D1 barrel to sample thalamic inputs. However, this explanation is unlikely to apply to the case of short-latency responses found at more than half a barrel width away from the D1 barrel. In these cases, the best explanation is that D1 thalamocortical afferents have failed to segregate properly (Erzurumlu and Jhavari, 1991) and have been retained in inappropriate barrels. Since the layer IV septal lesions also reduced the number of short-latency responses in surrounding barrels, aberrant thalamocortical axons must travel to the D1 barrel before sending a horizontal process to the neighboring barrel. There is some anatomical evidence for such horizontal collaterals during early development (Senft and Woolsey, 1991), and it is possible that some of these are retained in development by univibrissa rearing.

Plasticity has been found to be greater in layers II and III than IV at all the ages studied to date (P0-P56; Fox, 1992; Glasewski and Fox, 1994 and unpublished observations). At least two processes are likely to be involved in layer II/III plasticity: an increase in lateral excitation emanating from the D1 column and a decrease in vertical intracolumnar transmission in the deprived principal barrel (see Fox, 1992). The experiments reported here confirm the cortical origin of the cells participating in these effects, but unfortunately do not restrict the possible interlaminar pathways. Latency analysis suggests that excitation propagates from layers IV and $\mathrm{Vb}$ to layers II/III within the column, before radiating laterally to effect cells in neighboring barrels (Armstrong-James et al., 1992). Therefore, the pathway for increased lateral excitation to layers II/III could involve lateral projections from layer II, III, IV, or V. Anatomical evidence suggests that all three possible pathways send axons through layer IV (Lorente de No, 1922), and so could have been affected by the layer IV septal lesions.

The decreased responsiveness of layer II/III cells to stimulation of their principal vibrissa could be attributable partly to a failure of the normal vertical columnar connections to grow. Development of responses to principal vibrissa stimulation in layers II/III appears to depend on normal levels of synaptic activity (Fox et al., 1993). However, since a similar decrease in principal vibrissa efficacy is also seen in older animals (P28), it could also be due to downregulation of this synaptic link (Glazewski and Fox, 1994).

In this study, it was found that the principal vibrissa was slightly under-represented in barrels surrounding D1, but normal response levels were restored by lesions destroying more than about $40 \%$ of the D1 barrel. This could indicate that active inhibition of the principal vibrissa response was occurring due to increased levels of lateral inhibition generated by the DI barrel neurons. Lateral inhibitory processes are known to occur in somatosensory cortex from functional (Simons, 1985) and pharmacological studies (Dykes et al., 1984), and it is conceivable that the "experienced" inhibitory pathways might be selectively enhanced during development. A synapse-specific po- tentiation mechanism appears to exist in the cortex for inhibitory pathways (Komatsu and Iwakiri, 1993), and while it is not clear that inhibitory pathways are potentiated in visual cortex by monocular deprivation, intracortical inhibitory mechanisms certainly appear to suppress closed-eye inputs in monocularly deprived cats (Sillito et al., 1981). Rats chronically deprived from a young age do not show any changes in GAD levels, unlike adults (Akhtar and Land, 1991), where GAD changes occur rapidly in reply to alterations in the activity received from the periphery. However, the small changes in lateral inhibition that we see in developing animals may be below the resolution of the GAD technique, especially since lateral inhibitory connections would comprise only a small subset of all GABAergic terminals.

\section{Conclusions}

These results imply that univibrissa rearing causes changes in columnar and intercolumnar connections within the barrel cortex. Excitatory, and to some extent inhibitory, pathways appear to be involved. Any subcortical changes that occur either are not relayed to the cortex or are too small for us to detect. These findings suggest that it should be possible to use univibrissa rearing as a method for examining the pathways and mechanisms involved in cortical plasticity.

\section{References}

Akhtar ND, Land PW (1991) Activity dependent regulation of glutamic acid decarboxylase in the rat barrel cortex: effects of neonatal versus adult sensory deprivation. J Comp Neurol 307:200-213.

Armstrong-James M, Fox K (1987) Spatio-temporal convergence and divergence in the rat S1 "barrel cortex." J Comp Neurol 263:264281 .

Armstrong-James M, Callahan CA, Friedman MA (1991a) Thalamocortical mechanisms in the formation of receptive fields of rat barrel cortex neurons. I. Intracortical mechanisms. J Comp Neurol 303:193-210.

Armstrong-James M, Callahan C (1991b) Thalamocortical mechanisms in the formation of receptive fields of rat barrel cortex neurons. II. The contribution of ventroposterior medial thalamic neurons. $\mathbf{J}$ Comp Neurol 303:211-224.

Armstrong-James M, Fox K, Das-Gupta A (1992) The flow of excitation within the barrel cortex on striking a single vibrissa. J Neurophysiol 68:1345-1358.

Basbaum AI, Wall PD (1976) Chronic changes in the response of cells in adult cat dorsal horn following partial deafferentation: the appearance of responding cells in a previously non-responsive region. Brain Res 116:181-204.

Darien-Smith C, Gilbert CD (1994) Axonal sprouting accompanies functional reorganization in adult cat striate cortex. Nature 368:737740.

Daw NW, Fox K, Sato H, Czepita D (1992) The critical period for plasticity in the cat visual cortex. J Neurophysiol 67:197-202.

Devor M, Wall PD (1981) Effect of peripheral nerve injury on receptive fields of cells in the cat spinal cord. J Comp Neurol 199:277-291.

Dykes RW, Landry P, Metherate R, Hicks TP (1984) Functional role of GABA in the cat primary somatosensory cortex: shaping receptive fields of neurons. J Neurophysiol 52:1066-1093.

Erzurumlu RS, Jhavari S (1991) Thalamic axons confer a blue-print of the sensory periphery onto the developing rat somatosensory cortex. Dev Brain Res 56:229-234.

Fitzgerald M (1985) The sprouting of saphenous nerve terminals in the spinal cord following early postnatal sciatic nerve section in the rat. J Comp Neurol 240:407-413.

Fox K (1992) A critical period for experience dependent synaptic plasticity in the rat barrel cortex. J Neurosci 9:1128-1135.

Fox K, Armstrong-James M (1986) The role of the anterior intralaminar nuclei and $N$-methyl-D-aspartate receptors in the generation of spontaneous bursts in cortical neurons. Exp Brain Res 63:505-518.

Fox K, Schlaggar BL, O'Leary DMM (1993) The effect of post-synaptic 
activity blockade on development of barrel cortex. Soc Neurosci Abstr 19:616.

Garraghty PE, Kaas JH (1992) Functional reorganization in adult monkey thalamus after peripheral nerve injury. Neurorcport 2:747750 .

Glazewski S, Fox K (1994) The time course of changes in the barrel cortex of adolescent rats. Soc Neurosci Abstr 20.

Hamori J, Savy C, Madarasz M, Somogyi J, Tacaks J, Verley R, FarkasBargeton E (1986) Morphological alterations in subcortical vibrissal relays following vibrissal destruction at birth in the mouse. J Comp Neurol 254:166-183.

Hand PJ (1982) Plasticity of the rat cortical barrel system. In: Changing concepts of the nervous system (Morison AR, Strick PL, eds), pp 4968. New York: Academic.

Harris RM, Woolsey TA (1981) Dendritic plasticity in mouse barrel cortex following postnatal vibrissa follicle damage. J Comp Neurol 196:357-376.

Hokfelt T, Zhang X, Wiesenfeld-Hallin Z (1994) Messenger plasticity in primary sensory neurons following axotomy and its functional implications. Trends Neurosci 17:22-30.

Jacquin MF, Rhoades RW, Klein BG (1994) Structure function relationships in brainstem subnucleus interpolaris. XI. Effects of chronic whisker trimming from birth. J Comp Neurol, in press.

Juliano SL, Ma W, Eslin D (1991) Cholinergic depletion prevents expansion of topographic maps in somatosensory cortex. Proc Natl Acad Sci USA 88:780-784.

Komatsu Y, Iwakiri M (1993) Long-term modification of inhibitory synaptic transmission in developing visual cortex. Neuroreport 4:907910

Liu DM, Sirois DA, Gallo KM, Hand PJ (1992) Non-linear cortical functional representation changes following partial deafferentation of rat facial vibrissae. Soc Neurosci Abstr 18:57.

Loeb EP, Chang FLF, Greenough WT (1987) Effects of neonatal 6-hydroxydopamine treatment upon morphological organization of the posteromedial barrel subfield in mouse somatosensory cortex. Brain Res 403:113-120.

Lorente de No R (1922) La corteza cerebral del raton. Trab Lab Invest Biol Madrid 20:41-78.

McCasland JS, Bernado KL, Probst KL, Woolsey TA (1992) Cortical local circuit axons do not mature after early deafferentation. Proc Nat Acad Sci USA 89:1832-1836.

Merzenich MM, Kaas JH, Wall JT, Nelson RJ, Sur M, Felleman D (1983) Topographic reorganization of somatosensory cortical areas $3 \mathrm{~b}$ and 1 in adult monkeys following restricted deafferentation. Neuroscience 8:33-55.

Nicolelis MAL, Chapin JK, Lin RCS (1991) Thalamic plasticity induced by early whisker removal in rats. Brain Res 561:344-349.

Rasmusson DD (1988) Projection of digit afferents to the cuneate nucleus in the raccoon before and after partial deafferentation. J Comp Neurol 277:549-556.

Renehan WE, Crissman RS, Jacquin MF (1994) Primary afferent plas- ticity following partial denervation of the brainstem trigeminal complex in the postnatal rat. J Neurosci 14:721-739.

Rhoades RW, Chiaia NL, Mooney RD, Klein BG, Renehan WE, Jacquin MF (1987) Rcorganization of the peripheral projections of the trigeminal ganglion following neonatal transection of the infraorbital nerve. Somatosens Mot Res 5:35-62.

Schlaggar BL, Fox K, O'Leary DMM (1993) Postsynaptic control of plasticity in developing somatosensory cortex. Nature 364:623-626.

Senft SL, Woolsey TA (1991) Growth of thalamic afferents into mouse barrel cortex. Cereb Cortex 1:308-335.

Sillito AM, Kemp JA, Blakemore C (1981) The role of GABAergic inhibition in the cortical effects of monocular deprivation. Nature 291:318-320.

Simons DJ (1985) Temporal and spatial integration in the rat S1 vibrissa cortex. J Neurophysiol 54:615-635.

Simons DJ, Land PW (1987) Early experience of tactile stimulation influences organization of somatic sensory cortex. Nature 326:694697.

Waite PME (1984) Rearrangement of neuronal responses in the trigeminal system of the rat following peripheral nerve section. J Physiol (Lond) 352:425-445.

Waite PME, Cragg BG (1979) The effect of destroying the whisker follicles in mice on the sensory nerve, the thalamocortical radiation and cortical barrel development. Proc R Soc Lond [Biol] 204:41-55.

Waite PME, Li L, Ashwell KWS (1992) Developmental and lesion induced cell death in the rat ventrobasal complex. Neuroreport 3:485488.

Wall JT (1988) Variable organization in cortical maps of the skin as an indication of the lifelong adaptive capacities of circuits in the mammalian brain. Trends Neurosci 1 1:549-557.

Wall JT, Kaas JH, Sur M, Nelson RJ, Ferster D, Merzenich MM (1986) Functional reorganization in somatosensory cortical areas $3 \mathrm{~b}$ and 1 of adult monkeys after median nerve repair: possible relationships to sensory recovery in humans. J Neurosci 6:218-233.

Wiesel TN, Hubel DH (1963) Single cell responses in striate cortex of kittens deprived of vision in one eye. J Neurophysiol 26:10031017.

Wong-Riley M (1979) Changes in the visual system of monocularly sutured or enucleated cats demonstrable with cytochrome oxidase histochemistry. Brain Res 171:11-28.

Woolsey TA, Van der Loos H (1970) The structural organization of layer IV in the somatosensory region (S1) of the mouse cerebral cortex: the description of a cortical field composed of discrete cytoarchitectonic units. Brain Res 17:205-242.

Woolsey TA, Wann JR (1976) Areal changes in mouse cortical barrels following vibrissal damage at different post-natal ages. J Comp Neurol 170:53-66.

Zarzecki P, Witte S, Smits E, Gordon DC, Kirchberger P, Rasmusson DD (1993) Synaptic mechanisms of cortical representational plasticity: somatosensory and corticocortical EPSPs in reorganized raccoon cortex. J Neurophysiol 69:1422-1432. 